\title{
Modeling of Laser Vaporization and Plume Chemistry in a Boron Nitride Nanotube Production Rig
}

\author{
Peter A. Gnoffo*and Catharine C. Fay ${ }^{\dagger}$ \\ NASA Langley Research Center, Hampton, VA 23681-2199
}

\begin{abstract}
Flow in a pressurized, vapor condensation (PVC) boron nitride nanotube (BNNT) production rig is modeled. A laser provides a thermal energy source to the tip of a boron fiber bundle in a high pressure nitrogen chamber causing a plume of boronrich gas to rise. The buoyancy driven flow is modeled as a mixture of thermally perfect gases $\left(\mathrm{B}, \mathrm{B}_{2}, \mathrm{~N}, \mathrm{~N}_{2}, \mathrm{BN}\right)$ in either thermochemical equilibrium or chemical nonequilibrium assuming steady-state melt and vaporization from a $1 \mathrm{~mm}$ radius spot at the axis of an axisymmetric chamber. The simulation is intended to define the macroscopic thermochemical environment from which boron-rich species, including nanotubes, condense out of the plume. Simulations indicate a high temperature environment $(T>4400 \mathrm{~K})$ for elevated pressures within $1 \mathrm{~mm}$ of the surface sufficient to dissociate molecular nitrogen and form $\mathrm{BN}$ at the base of the plume. Modifications to Program LAURA, a finite-volume based solver for hypersonic flows including coupled radiation and ablation, are described to enable this simulation. Simulations indicate that high pressure synthesis conditions enable formation of BN vapor in the plume that may serve to enhance formation of exceptionally long nanotubes in the PVC process.
\end{abstract}

\section{Introduction}

The future of manned and unmanned space flight and exploration depends on economical access to space. A key enabler of economic access to space is the use of multifunctional lightweight materials. Boron nitride nanotube (BNNT) composites offer distinct advantages for enhanced survivability during long-term exploration flights. BNNTs are structurally a close analog of carbon nanotubes (CNTs), with the carbon atoms alternately substituted with boron and nitrogen atoms. BNNTs are durable at low temperature in space $(-157 \mathrm{C})$ and exhibit good thermal stability up to $800 \mathrm{C}$ with a low coefficient of thermal expansion. Their strength-to-weight ratios and stiffness are greater than $95 \%$ of carbon nanotube values with an elastic modulus approaching $1 \mathrm{TPa}$. (The fibers are calculated to be the world's strongest structural fiber above $400 \mathrm{C}$.) Boron has one of the largest neutron capture cross sections of all elements in the periodic table. Nitrogen has a larger neutron capture cross section than carbon. Consequently, BNNT materials have great potential for radiation shielding applications. Their high strength also makes BNNT fabrics well suited for deployable aerobrake surfaces, offering dual use opportunities for radiation shielding in transit and deployable aerobrake on entry into a planetary atmosphere. These materials can enable development of aerospace structures with both impact resistance and radiation shielding capability, thereby improving reliability and durability for long-term missions.

${ }^{*}$ Senior Research Engineer, Aerothermodynamics Branch; AIAA Fellow

${ }^{\dagger}$ Senior Materials Engineer, Advanced Materials and Processing Branch 
Arenal et al. ${ }^{1}$ have recently reviewed BNNT production methods and associated nanotube properties. Not included in this review is a description of a recently developed and unique hightemperature, pressurized vapor condensation (PVC) method. ${ }^{2}$ The NASA Langley Research Center (LaRC), National Institute of Aerospace (NIA) and Jefferson Sciences Association/DoE team discovered that this novel synthesis method produces thin, long, high aspect ratio, highly crystalline BNNTs using a conventional laser at high pressure. ${ }^{2}$ The PVC method appears to minimize tube defects and create exceptionally long (order $\mathrm{mm}$ ) tubes. The synthesis of longer tubes is advantageous for structural reinforcement applications, where it is more likely that the desired strength properties will extend from the nanoscale to the macroscale.

Macroscopic details of the PVC production process (plume formation, species densities, temperatures, flow rates) ensuing from laser energy deposition on a boron sample in a pressurized test rig are modeled herein. The simulations here initially assume axisymmetric, single phase flow. Neither the possible presence of boron droplets sputtered from the boron source nor the nucleation of solids from the plume are included in these initial simulations. The intent here is to guide a subsequent experimental program to measure the thermochemical environment in the plume. The more critical components of nanotube formation on the molecular dynamics level (homogeneous nucleation, heterogeneous nucleation, surface catalysis) will require input from the macroscopic environment to be understood. Both the macroscopic environment and the molecular dynamics must be accurately modeled in order to optimize BNNT production rates and ultimately create an industrial scale processing capability. Our objective is a coordinated modeling effort to address these challenges to enable an industrial level BNNT production. To this end, we focus on the flow rates of $\mathrm{BN}$ vapor as a function of pressure to possibly explain improved qualities of nanotubes produced with the PVC method.

\section{Nomenclature}

\section{Roman symbols}

$A_{r}, B_{r} \quad$ Arrhenius rate parameters, Eq. 1

$c$

$g$

$h$

$\Delta H_{f}$ $\Delta H_{\text {vap }, B}^{0}$ $k$

$K_{c}$

$\dot{m}$

$\dot{\tilde{m}}$

$n$

$p$

$q$

$r$

$R$

$t$

$T$

$V_{n}$

$z$ mass fraction

gravitational acceleration

enthalpy per unit mass

heat of formation

heat of vaporization for boron

reaction rate coefficient

equilibrium constant

mass loss rate, $\mathrm{mg} / \mathrm{mm}^{2}-\mathrm{hr}$

integrated $\dot{m}, \mathrm{mg} / \mathrm{hr}$

number of moles

pressure

heating rate

radius

universal gas constant

time

temperature

velocity normal to wall

height above droplet

\section{Greek symbols}

$\alpha \quad$ absorbed radiation fraction

$\epsilon \quad$ emissivity

$\rho$ density

$\sigma \quad$ Stefan-Boltzmann constant

$\chi \quad$ mole fraction

\section{Subscripts}

0 conditions in chamber

act activation

$b$ backward rate

cond conduction

conv convection

$f \quad$ forward rate

melt property of droplet

$r \quad$ reaction number

$s \quad$ species

sat saturation

vap vapor

$w \quad$ wall 


\section{Pressurized Vapor Condensation (PVC) Method - Process Description}

The PVC method has been described by Smith et al. ${ }^{2,3}$ The process is summarized here so that the models and simulations may be better understood in relation to actual conditions.

\section{A. System Components}

A schematic of the PVC system for producing Boron Nitride NanoTubes (BNNT) is presented in Figure 1. A laser beam (red line) enters a pressurized chamber (component $\mathrm{H}$ ) through a window (component $\mathrm{G}$ ) at the top of the chamber. A feedstock of bundled boron fibers (component $\mathrm{K}$ ) is slowly guided into the chamber using the target feed drive (component $\mathrm{J}$ ) and target adjusters (component L). A nitrogen supply line (component I), flow controls (component O), and exhaust flow meter (component D) are all used to maintain a constant pressure environment in the chamber. The laser is focused toward the tip of the boron fiber bundle in the chamber.

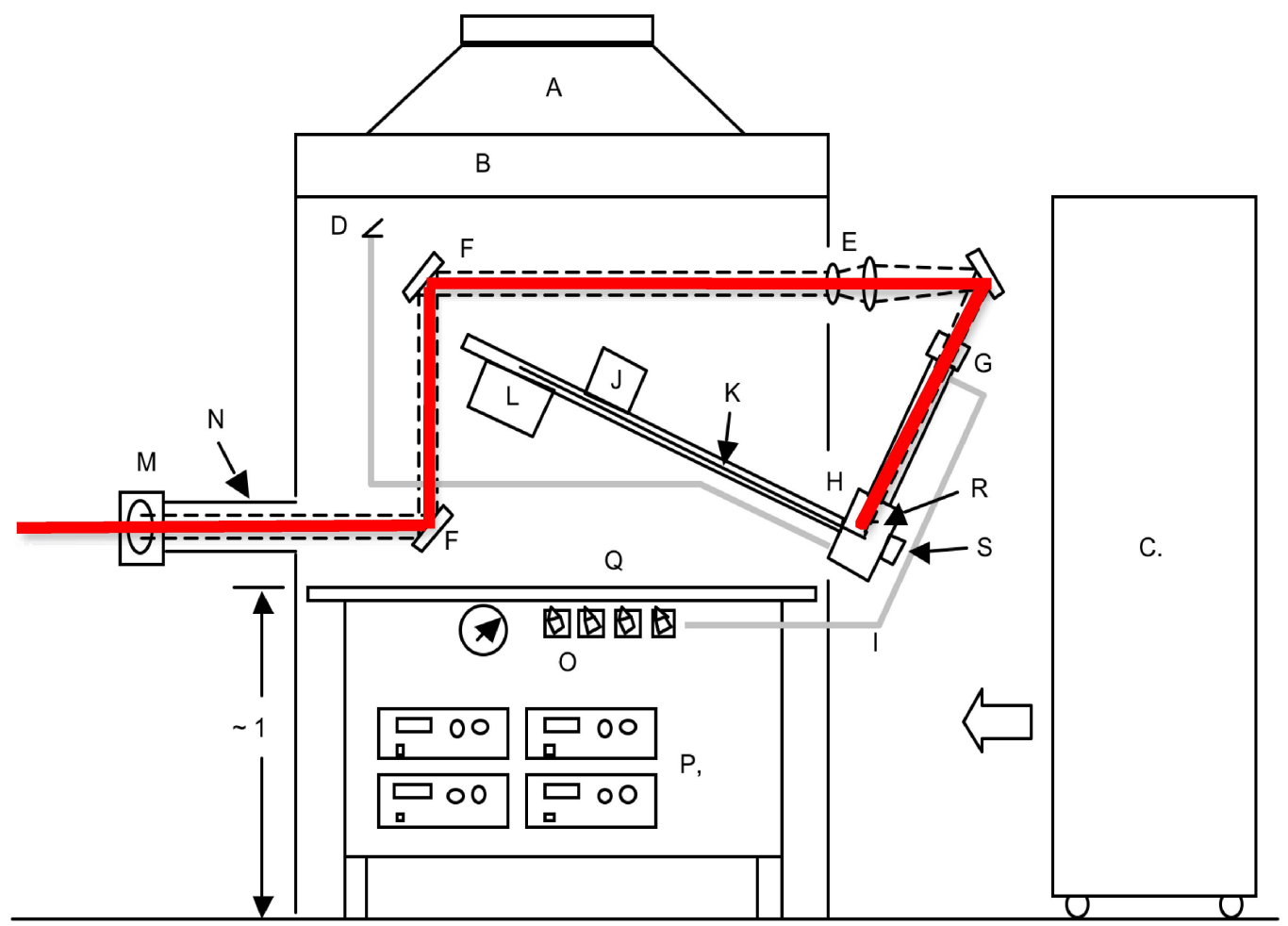

Figure 1. (Provided by Michael Smith, BNNT LLC) Schematic of the BNNT production rig using PVC method: A. Exhaust to building exterior; B. HEPA filter (0.3 micron); C. Sliding, bullet-proof, protective shell; D. Chamber exhaust flowmeter; E. Beam-shaping optics; F. Turning mirrors; G. ZnSe Input window; H. Pressure chamber; I. Nitrogen supply line; J. Target feed drive; K. Target (B or BN); L. Vertical/Horizontal target adjusters; M. Pico-motor-controlled turning mirror; N. CO2 laser beam; O. Pressure flow controls; P. Electronic controls (target and beam manipulation); Q. Optics table; R. Condenser Loop; S. View port (video cameras).

\section{B. Formation of Molten Boron Droplet}

An illustration of the interaction of the laser and the boron fiber bundle (not to scale) is presented in Fig. 2. The laser power and focus is adjusted to strike the boron fiber bundle in a way that 
enables a boron droplet to suspend by surface tension from the end of the fiber bundle. The laser then directly strikes only the droplet. Energy is conducted and re-radiated from the droplet into the fiber bundle. In a perfectly tuned system all mass loss is through vaporization, the melt rate to replenish the droplet exactly matches the mass loss rate through vaporization, and the fiber bundle is continuously fed into the chamber to keep the interaction location fixed within the chamber. If delivered power is too great the droplet boils and drops off the end of the fiber bundle. Any such perfectly tuned combination of delivered laser power and constant feed rate of the boron fiber bundle into the chamber without any droplets falling off is considered a steady state vaporization condition. It requires a balance of mass conversion from solid phase to liquid phase to gas phase. It requires a corresponding balance of energy to drive these phase changes from the laser to the droplet to the fiber bundle along with convective and radiative losses to the surrounding system. The intent of the simulations to be described in the next section is to model the steady state vaporization.

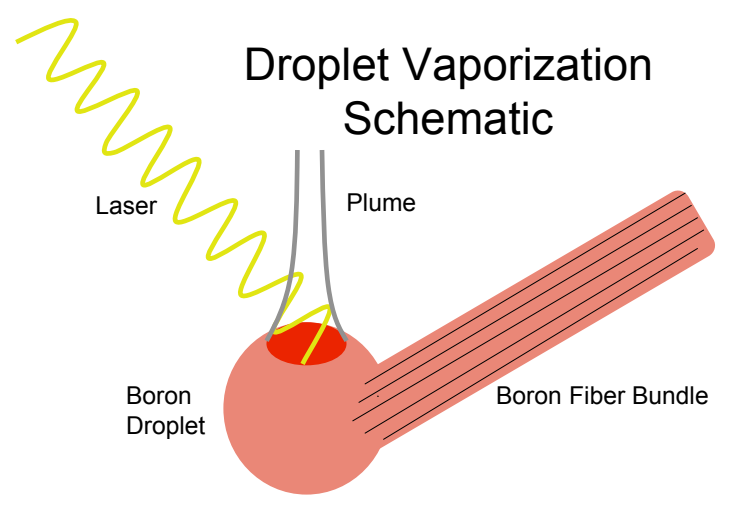

Figure 2. Laser aimed at the tip of a boron fiber bundle causes molten droplet to suspend from the tip, held there by surface tension, and a plume of boron-rich gas rises from the hot spot driven by buoyancy. Boron nitride nanotubes form on a wire condenser loop (not shown) when the rising plume contacts it.

\section{Formation of Boron Nitride Nanotubes on Condenser Wire}

Also shown in Fig. 2 is a plume of hot gas fed by vaporization off the droplet. The plume rises by buoyancy in which the low density, hot gas in the plume base is displaced vertically by the higher density, cooler nitrogen gas surrounding it. As the nitrogen is drawn in to the base of the plume it is heated and reacts with the boron vapor. Not shown in Fig. 2 is a condenser wire loop which serves as a nucleation site for BNNTs and other boron species when the plume flows over it. The condenser wire loop (component R) in Fig. 1 can be pulled like a clothesline on pulleys within the chamber. This action draws condensate out of the way of the plume and exposes fresh nucleation sites. In the configuration shown in Fig. 1 the condensate is harvested after the system is powered off and the chamber can be de-pressurized and opened. Simulations of the gas phase in the plume are intended to define the constituents and thermodynamic environment available for nucleation. 


\section{Modeling}

\section{A. Computational Domain, Grid, and Boundary Conditions}

The discretization of an idealized chamber is presented in Fig. 3. The model assumes that the actual plume is axi-symmetric and that its evolution within the actual chamber up to the condenser wire is not strongly effected by the orientation of chamber walls far removed (50 to 100 plume diameters) from the plume axis. This assumption enables creation of an idealized, axi-symmetric chamber to simplify the simulation and enable parametric investigations in reasonable time. The axis of the chamber corresponds to the axis of the plume as seen in the center of the figure. The idealized chamber radius is $5 \mathrm{~cm}$. The idealized chamber height is $10 \mathrm{~cm}$. The radius of the laser spot in the droplet is set to $1 \mathrm{~mm}$ for all simulations. At time $t=0$ the chamber is filled with molecular nitrogen at temperature $T_{0}$, pressure $p_{0}$, and density $\rho_{0}$ with zero velocity throughout.

The top and bottom boundaries, except for the $1 \mathrm{~mm}$ radius spot heated by the laser, is treated as a cold $\left(T_{w}=300 . \mathrm{K}\right)$, no-slip wall. Species mass fractions at the walls are computed assuming chemical equilibrium at the wall temperature and the locally computed elemental mass fractions from the elemental continuity equations. The left boundary is the axis of symmetry. The right boundary is treated as a porous wall to maintain constant pressure in the chamber in an environment in which mass and energy are added continuously. In the actual chamber nitrogen feed and purge lines (grey lines in Fig. 1) purge gas from the chamber and replace it with molecular nitrogen to maintain constant pressure. The porous wall boundary condition replaces this function while maintaining an axisymmetric flow environment. It computes the difference between the local value of pressure at the wall and the target pressure, $\Delta p_{w}=p_{w}-p_{t a r}$. It is derived from Bernoulli's Equation and assumes an idealized porosity with zero losses. If $\Delta p_{w}>0$ then flow at local conditions is directed out of the chamber with velocity $V_{n}=-\sqrt{2 \Delta p_{w} / \rho_{w}}$. If $\Delta p_{w}<0$ then pure nitrogen flow at $T_{0}=300 \mathrm{~K}$ is directed into the chamber with velocity $V_{n}=\sqrt{-2 \Delta p_{w} / \rho_{0}}$.

In the lower right inset of Fig. 3 the domain above the $1 \mathrm{~mm}$ radius irradiated spot is featured. In this simulation the droplet surface has no curvature. In fact, the largest and potentially significant difference between this idealized domain and the actual domain is that the idealized domain treats the irradiated surface of the droplet as a spot on the floor of the chamber. In the actual chamber, gas can rise from beneath the droplet suspended from the end of the fiber bundle. In the present simulations, gas flows along a cold wall before feeding the base of the plume. Possible consequences of this simplification are discussed in a later section. The cell size normal to the wall in the nominal grid is $10^{-7} \mathrm{~m}$. The tight spacing here helps maintain stability in the very early evolution of the plume when the spot is first irradiated. The cell size tangent to the wall over the $1 \mathrm{~mm}$ radius is a constant $210^{-5} \mathrm{~m}$. Mesh size grows in the radial direction by a factor of 1.1 beyond the $1 \mathrm{~mm}$ edge of the droplet. Mesh size grows by the same 1.1 factor in the vertical direction. Mesh growth is terminated when the cell dimension achieves $2 \mathrm{~mm}$. This grid generation algorithm maintains a fine spacing in the radial direction in the core of the chamber to capture diffusion across the edge of the plume. Additional discussion of grid resolution will be presented in a later section on Grid Convergence. The boundary condition across the $1 \mathrm{~mm}$ radius at the bottom of the domain defines the surface response model. The formulation of this boundary condition is discussed subsequently in the section titled Material Response Model.

\section{B. Gas Properties}

The nominal atmosphere inside the pressurized chamber is $100 \% \mathrm{~N}_{2}$. Parameter studies also consider the effects of noble gas ( $\mathrm{He}$ or $\mathrm{Ar}$ ) in the chamber. The B-N system is assumed to include $\left(\mathrm{B}, \mathrm{BN}, \mathrm{N}, \mathrm{N}_{2}\right.$, and $\mathrm{B}_{2}$ ) - all in the gas phase. An option for multiple phases in the plume is not yet considered and so the simulations are intended to describe conditions up to the first nucleation 


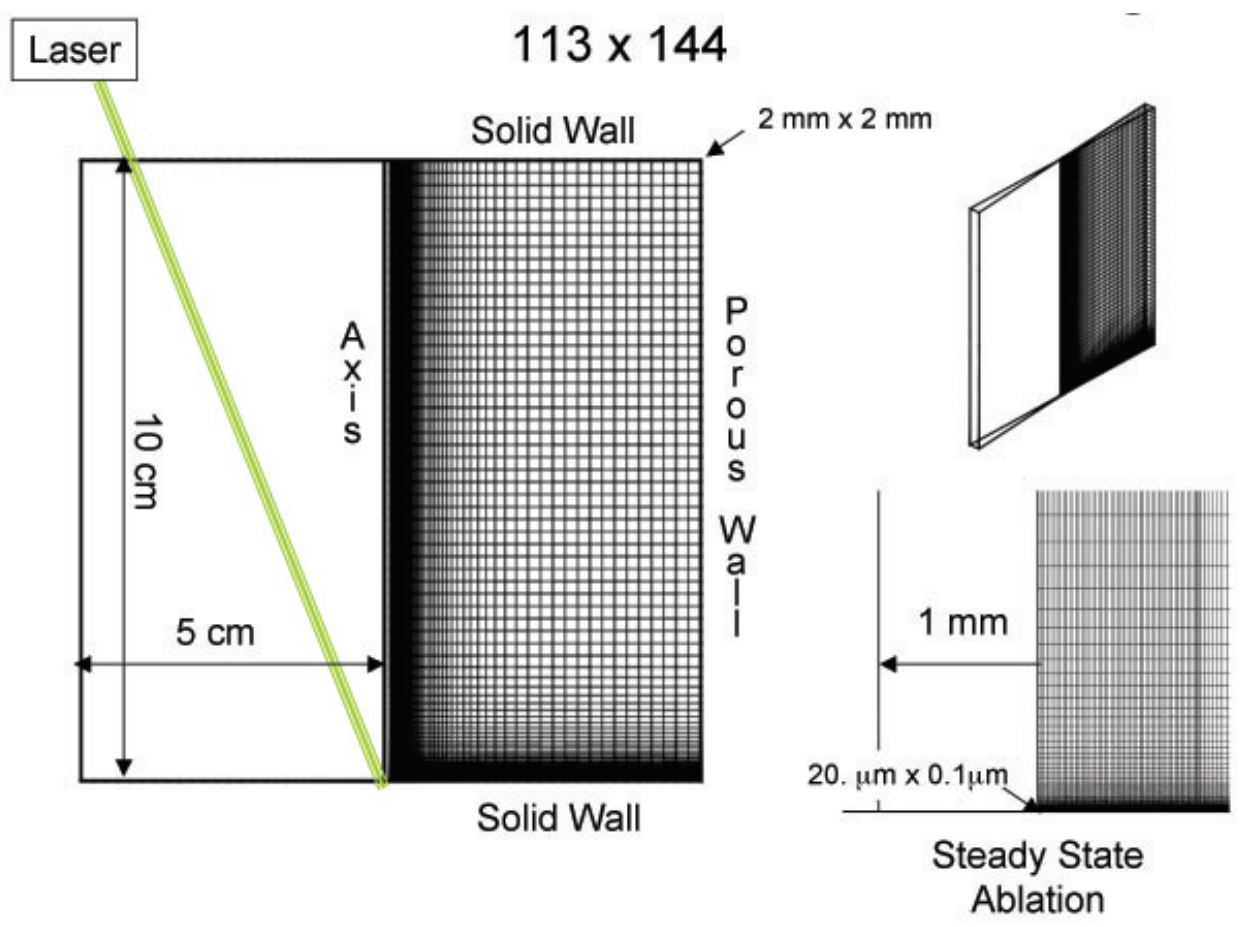

Figure 3. Boundary conditions and grid (113 x 144 cells) used to discretize idealized, axisymmetric pressure chamber $(5 \mathrm{~cm}$ radius $\times 10 \mathrm{~cm}$ height). Upper right inset shows perspective of 5 degree wedge shaped domain. Lower right inset shows detail above $1 \mathrm{~mm}$ radius spot where the laser heats the droplet at the tip of the boron fiber bundle.

event. Curve fits for thermodynamic properties of these species are obtained from the CEA code. ${ }^{4}$ Transport properties are calculated as functions of collision cross-sections and temperature. ${ }^{5}$ Collision cross sections for the B-N system were approximated by using the corresponding collision cross sections in the $\mathrm{C}-\mathrm{N}$ system ${ }^{6-8}$ along with the appropriate molecular weights of the colliding pairs in the B-N system. A spot check with an evaluation of B-B cross sections ${ }^{9}$ at $2000 \mathrm{~K}$ indicate they are approximately $20 \%$ higher than the corresponding C-C cross sections. ${ }^{10}$

In the case of flow in chemical equilibrium the elemental continuity equations are solved and a free energy minimization is implemented in every control volume to solve for species mass fractions as a function of elemental mass fraction, temperature, and pressure. ${ }^{11}$

Early equilibrium simulations had been run with only a four species model that neglected $\mathrm{B}_{2}$. These simulations indicated that the presence of $\mathrm{B}_{2}$ significantly diminished the amount of $\mathrm{BN}$ in the upper part of the plume. A quick check on the possible influence of reaction path to equilibrium was then initiated. The intent here was to see how BN, created in the hot base of the plume, was consumed as the gas rises and cools. Is it credible that BN levels could freeze (remain relatively constant) as the plume rises and cools, even at elevated pressures? This question regarding the qualitative effects of kinetics in a rising plume is addressed by approximating a kinetic model for the B-N system with a C-N system template as shown in Table 1. (An experimentally verified kinetic model for the B-N system has not yet been identified.) Column 1 is the reaction number, Column 2 shows a proposed reaction in the B-N system and column 3 shows the corresponding template reaction from the $\mathrm{C}-\mathrm{N}$ system. Column 4 presents the pre-exponential factor of the Arhenius rate formulation as defined for the template reaction, ${ }^{12,13}$ where the Arrhenius rate coefficients for 
forward and backward reactions are given by

$$
\begin{aligned}
k_{f, r} & =A_{r} T^{B_{r}} \exp \left(-T_{r, a c t} / T\right) \\
k_{b, r} & =k_{f, r} / K_{c, r}(T)
\end{aligned}
$$

The activation temperature $T_{r, \text { act }}$ for reaction $r$ is approximated using the heats of formation of reactants and products compiled in Table 2 .

$$
T_{r, a c t} \approx T_{r}^{*}=\left(\sum_{s}^{\text {products }} n_{s, r} \Delta H_{f, s}-\sum_{s}^{\text {reactants }} n_{s, r} \Delta H_{f, s}\right) / R
$$

Column 5 of Table 1 presents the proposed activation temperature for the B-N system reaction as calculated from Eq. 3. Column 6 presents the activation temperature used in the template C-N system and column 7 presents the value of $T_{r}^{*}$ as a reference condition for the credibility of the approximation in Eq. 3. $T_{r}^{*}$ is within $3 \%$ of the experimentally determined activation temperature for reactions 1-3. The approximation is not so good with reactions 4 and 5 where differences are $47 \%$ and $-25 \%$, respectively. The dissociation of $\mathrm{N}_{2}$ by collision with any generic partner is included in the model. It does not appear in Table 1 because its Arrhenius rate coefficients are readily available and do not require a template.

Table 1. Chemical Kinetic Models for B-N and C-N Systems

\begin{tabular}{ccccccc}
\hline & B-N system & C-N system & pre-expon. & proposed & template & template \\
$\mathrm{r}$ & proposed reactions & template reactions & $A_{r}$ & $T_{r, a c t}, \mathrm{~K}$ & $T_{r, a c t}, \mathrm{~K}$ & $T_{r}^{*}, \mathrm{~K}$ \\
\hline 1 & $\mathrm{~B}_{2}+\mathrm{M}<=>2 \mathrm{~B}+\mathrm{M}$ & $\mathrm{C}_{2}+\mathrm{M}<=>2 \mathrm{C}+\mathrm{M}$ & $3.710^{14}$ & 34914 & 69900 & 71637 \\
2 & $\mathrm{BN}+\mathrm{M}<=>\mathrm{B}+\mathrm{N}+\mathrm{M}$ & $\mathrm{CN}+\mathrm{M}<=>\mathrm{C}+\mathrm{N}+\mathrm{M}$ & $2.510^{14}$ & 66834 & 87740 & 90717 \\
3 & $\mathrm{~N}_{2}+\mathrm{B}<=>\mathrm{BN}+\mathrm{N}$ & $\mathrm{N}_{2}+\mathrm{C}<=>\mathrm{CN}+\mathrm{N}$ & $1.110^{14}$ & 46870 & 23200 & 22986 \\
4 & $\mathrm{BN}+\mathrm{B}<=>\mathrm{B}_{2}+\mathrm{N}$ & $\mathrm{CN}+\mathrm{C}<=>\mathrm{C}_{2}+\mathrm{N}$ & $5.010^{13}$ & 31919 & 13000 & 19077 \\
5 & $\mathrm{~B}_{2}+\mathrm{N}_{2}<=>2 \mathrm{BN}$ & $\mathrm{C}_{2}+\mathrm{N}_{2}<=>2 \mathrm{CN}$ & $7.110^{13}$ & 14950 & 5330 & 3993 \\
\hline
\end{tabular}

Table 2. Enthalpy of Formation ${ }^{14}$

\begin{tabular}{cl|cl|cl}
\hline species & $\Delta H_{f}, \mathrm{~kJ} / \mathrm{mol}$ & species & $\Delta H_{f}, \mathrm{~kJ} / \mathrm{mol}$ & species & $\Delta H_{f}, \mathrm{~kJ} / \mathrm{mol}$ \\
\hline $\mathrm{B}$ & $560 \pm 12$ & $\mathrm{C}$ & $716.67 \pm .46$ & $\mathrm{~N}$ & $472.68 \pm 0.1$ \\
$\mathrm{BN}$ & $477 \pm 125$ & $\mathrm{CN}$ & $435.1 \pm 10$ & & \\
$\mathrm{~B}_{2}$ & $829.7 \pm 33.5$ & $\mathrm{C}_{2}$ & $837.7 \pm 3.8$ & $\mathrm{~N}_{2}$ & 0 \\
\hline
\end{tabular}

\section{Material Response Model}

Two material response models have been tested. The first one simply allows the user to specify a uniform droplet surface temperature and a uniform vaporization mass flow rate as determined from experimental observation. The second one enables the computation of a spatially varying droplet temperature and mass flow from the droplet using a steady-state vaporization/melt approximation. An equilibrium vapor pressure is assumed for gaseous boron $\mathrm{B}(\mathrm{g})$ over the molten boron droplet $\mathrm{B}(\mathrm{l})$ at the tip of the solid boron fiber bundle. The boiling point of boron at $p=1 \mathrm{bar}=10^{5} \mathrm{~N} / \mathrm{m}^{2}$ is 
$T_{v a p}=4137.895 \mathrm{~K}$ and the corresponding enthalpy of vaporization is $\Delta_{v a p} H_{B}^{0}=480.344 \mathrm{~kJ} / \mathrm{mol}^{14}$ (Uncertainties were not provided for these calculated values. For reference, the uncertainty in the heat of formation of boron gas is $12 \mathrm{~kJ} / \mathrm{mol}$.) The Clausius-Clapeyron Equation is used to compute the equilibrium vapor pressure of boron as a function of droplet surface temperature.

$$
\ln \frac{p_{B, 2}}{p_{B, 1}}=-\frac{\Delta_{v a p} H_{B}^{0}}{R}\left(\frac{1}{T_{2}}-\frac{1}{T_{1}}\right)
$$

Table 3 provides a convenient reference for the boiling point of boron computed with Eq. 4 as a function of pressure levels used in this study. Chamber pressure in units of psig are used throughout, consistent with the experimental apparatus. Table 3 also shows these pressures in units of $\mathrm{Pa}$ and atmospheres.

Table 3. Boiling Point of Boron

\begin{tabular}{cccc}
\hline $\mathrm{p}, \mathrm{psig}$ & $\mathrm{p}, \mathrm{Pa}$ & $\mathrm{p}, \mathrm{atm}$ & $\mathrm{T}, \mathrm{K}$ \\
\hline 0 & $1.0132510^{5}$ & 1 & 4138. \\
50 & $4.4606210^{5}$ & 4.4 & 4629. \\
100 & $7.9080010^{5}$ & 7.8 & 4852. \\
200 & $14.802810^{5}$ & 14.6 & 5122. \\
400 & $28.592810^{5}$ & 28.2 & 5439. \\
800 & $56.171310^{5}$ & 55.4 & 5808. \\
\hline
\end{tabular}

A rigorous simulation would track the energy flux from the gas through the droplet and into the fiber bundle. A simplifying steady-state vaporization approximation is made to facilitate parametric studies. In the steady state vaporization approximation an energy balance across the liquid - gas interface of the droplet is evaluated. With reference to Fig. 4 the absorbed energy entering the

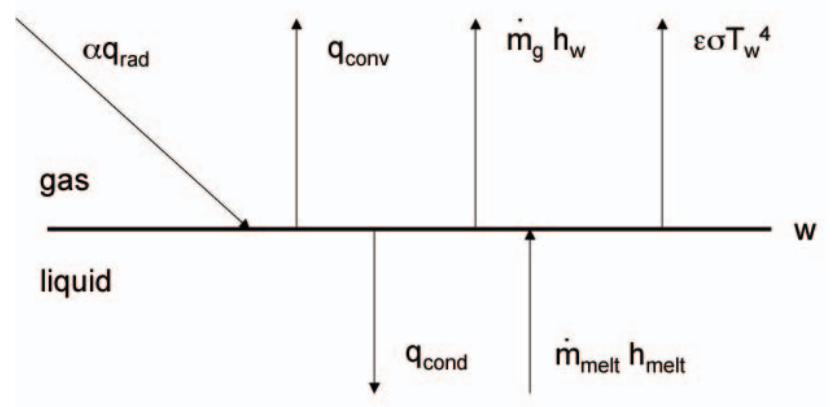

Figure 4. A schematic of energy flux crossing the interface of the droplet surface and the atmosphere at the base of the plume.

interface from above (the gas side) is the laser radiation $\alpha q_{\text {rad }}$. The energy leaving the interface through the gas phase by molecular transport processes is $q_{c o n v}$. This term includes conduction and diffusion of multiple species in the gas phase. The energy re-radiated from droplet surface into free space is $\epsilon \sigma T_{w}^{4}$. The energy carried by vaporization into the base of the rising plume is $\dot{m}_{g} h_{w}$. The energy approaching the interface from the liquid below is carried by the melt mass flux $\dot{m}_{\text {melt }} h_{\text {melt }}$. The energy leaving the interface in to the droplet is represented by $q_{\text {cond }}$. In the steady state approximation we assume that the melt rate is balanced by the vaporization rate 
so that the size of the droplet remains constant and there is no accumulation of energy in the droplet. Also, the conduction of energy into the droplet $q_{\text {cond }}$ is assumed to balance the melt flux of energy approaching the interface $\dot{m}_{\text {melt }} h_{\text {melt }}$. All of these balances, represented by Eq. 5 with $q_{\text {cond }}$ canceling $\dot{m}_{m e l t} h_{m e l t}$, implicitly assume a one-dimensional variation of properties .

$$
\alpha q_{\text {rad }}=\epsilon \sigma T_{w}^{4}+q_{\text {conv }}+\dot{m}_{g} h_{w}
$$

In reality there are losses through the sides of the droplet that are not simulated in the idealized domain. Consequently, we will lump the effect of these losses into the parameter $\alpha$ which already includes the absorption of radiation from the laser at a non-orthogonal angle to the droplet surface. We ultimately expect that $\alpha$ is a parameter that can be adjusted to match observed recession rates of the boron fiber bundle. We must also confirm that the assumption of a constant droplet size $\left(\dot{m}_{m e l t}=\dot{m}_{g}\right)$ can be achieved in the PVC process.

\section{Numerical Method}

Program LAURA ${ }^{11,15}$ simulates the coupled radiation and ablation in the shock layer over a vehicle entering a planetary atmosphere at hypersonic velocities. This code was chosen as a starting point for simulation of the production rig because the algorithms for dealing with high temperature, reacting gas mixtures and tightly coupled ablation and radiation for carbon based ablators are already well established. It uses Roe's averaging ${ }^{16}$ with Harten's entropy fix ${ }^{17}$ and Yee's Symmetric Total Variation Diminishing ${ }^{18}$ algorithms for solving inviscid flux. Central differences are used for viscous flux terms.

Simulation of the production rig required new modifications to the code including: (1) addition of boron species $\left(\mathrm{B}, \mathrm{BN}, \mathrm{B}_{2}\right)$ to thermodynamic and transport property data sets; (2) resetting a surface energy balance equation ${ }^{19}$ under a laser radiation source based on equilibration of atomic boron vapor pressure with a liquid boron source; (3) adding buoyancy terms (gravitational field) to the momentum equations; and, (4) adding a porous wall boundary condition to mimic a pressure relief valve in the system to maintain constant pressure as mass and energy are added to the system. Items 1,2 , and 4 have already been discussed in the previous section on modeling. Item 3 is easily accommodated by adding the source term $\rho g$ to the z-momentum equation.

Conversion of a dependent variable set from species densities and energy to species partial pressures and energy have addressed some preconditioning issues in the application of a hypersonics flow solver to a nearly incompressible flow domain though some stability issues persist. These issues are addressed by running simulations with first-order time accuracy with $\Delta t=1 \cdot 10^{-6} \mathrm{~s}$. Ten subiterations are engaged before advancing to the next time step. Each sub-iteration uses implicit line relaxation extending from the lower wall and droplet surface to the upper wall.

\section{Plume Simulations}

\section{A. Parameter Space}

Nominal conditions for simulated PVC process are $p_{0}=200 \mathrm{psig}, T_{0}=300 \mathrm{~K}, \rho_{0}=16.617 \mathrm{~kg} / \mathrm{m}^{3}$, in a molecular nitrogen atmosphere. As noted by Smith et al., ${ }^{2}$ an elevated pressure in the PVC method is found to yield exceptionally long nanotube lengths (estimated to at least $1 \mathrm{~mm}$ based on ability to spin fibrils into $1 \mathrm{~mm}$ diameter yarn). Nanotubes may also be created at atmospheric pressure levels ${ }^{20}$ but reported tube lengths at this condition are much shorter at $100 \mathrm{~nm}$.

Reasons for longer nanotube length under pressure are not rigorously understood. Modeling of the nucleation process with molecular dynamics ${ }^{21}$ and density functional theory ${ }^{22}$ are required to understand the key environmental factors at elevated pressures. Wang and Yang $^{23}$ suggest $^{2}$ 
recently developed techniques of "nanothermodynamics" can also provide insight into the nucleation process. In all of these approaches the nucleation modeling must be informed by the macroscopic environment (temperature, pressure, species, residence time) provided here.

Simulations of the macroscopic environment provide insights into the possible mechanisms through which the nucleation rates are enhanced. Certainly, the elevated pressures increase the collision rates of the component particles with the nucleation site. As will be seen in the subsequent sections, raising the pressure levels also raises the level of BN molecules directly available for nucleation without the need to catalyze dissociation of $\mathrm{N}_{2}$ in a liquid boron nucleation site. If condensation of $\mathrm{BN}$ molecules at the tip of a developing nanotube is a possible growth mechanism then it may prove to be a critical process to enable growth of exceptionally long BN nanotubes.

The parameter space for which simulations are executed include chamber pressure levels of 0 , 50, 100, 200, 400, and 800 psig. The simulated chamber atmospheres include $\chi_{N_{2}}=1, \chi_{N_{2}}=0.5$ and $\chi_{H e}=0.5$, and $\chi_{N_{2}}=0.5$ and $\chi_{A r}=0.5$. The power levels delivered to a $1 \mathrm{~mm}$ radius spot after subtracting losses include $.05,0.1,0.2$, and $2.0 \mathrm{~kW}$. All of these simulations are intended to provide insight regarding their effect on the plume environment. The flow rates of BN gas in the plume are highlighted because of their potential importance to a tip growth mechanism. Only simulations using the steady state vaporization boundary condition are provided here in which mass loss rate and droplet temperature are computed as part of the boundary condition.

\section{B. Grid Convergence for Nominal Conditions}

The grid generation algorithm for the nominal condition simulations was described previously in the section Computational Domain, Grid, and Boundary Conditions. A grid convergence study is presented here to evaluate any effects of grid resolution on computed results. The fine grid and coarse grids use minimum mesh sizes that are a factor of two finer and coarser, respectively, than the nominal grid. The fine and coarse grids use a factor of two smaller and greater, respectively, time step of $\Delta t=1.10^{-6} \mathrm{~s}$ used on the nominal grid simulations. The maximum allowed grid size, $2 \mathrm{~mm}$, is unchanged among all three grids. Consequently, grid resolution far from the plume is equivalent. The study focuses on resolution at the plume base and across the radial edge of the rising plume.

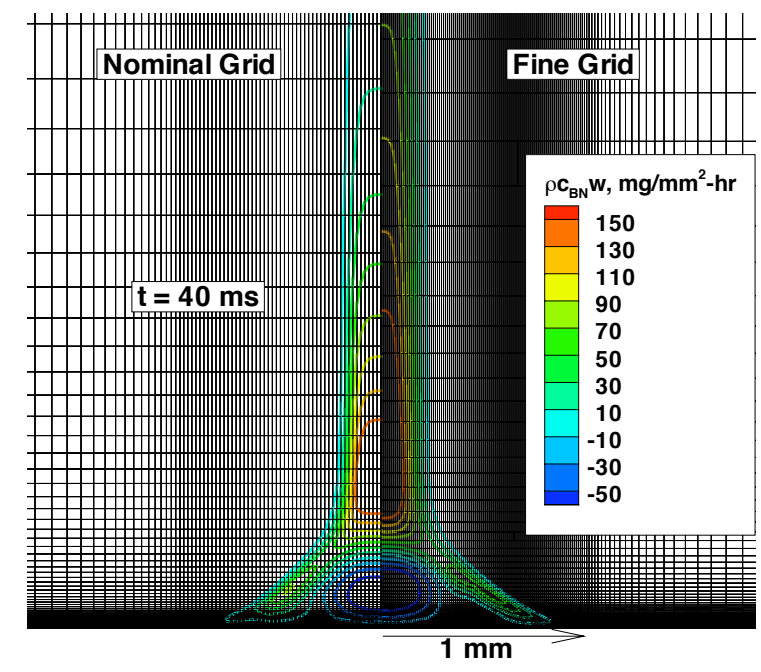

Figure 5. Contour lines of BN flow rates in the plume over an irradiated droplet of Boron are shown. Left side shows results for nominal grid. Right side shows results for fine grid. 
Fig. 5 presents a composite contour plot of the nominal grid solution on the left and the fine grid solution on the right. The plume axis rises vertically in the center of the figure. The contours indicate the vertical flow rate of the BN species in units of $\mathrm{mg} / \mathrm{mm}^{2}$-hr. (Nanotube production rates are most often quoted in units of $\mathrm{mg} / \mathrm{hr}$ in the literature. Because the base radius of the plume base is $1 \mathrm{~mm}$ these units provide a convenient reference.) Note the concentric blue oval contour lines at the base of the plume. Negative values here indicate a recirculating flow in which the velocity is approaching the droplet surface. The foot of the plume is fed by cold, molecular nitrogen. As it encounters the thermal layer above the irradiated spot the temperature increases sufficiently to enable some dissociation of molecular nitrogen that reacts with atomic boron rising from the droplet. A slight, unsteady pulsing of the plume is evident early in its evolution on the fine grid. The pulsing is not evident in the nominal grid simulation and eventually damps out on the fine grid. (Unsteady motion persists at higher absorbed laser power levels as will be discussed subsequently.)

Fig. 6 presents the centerline variation of plume properties as a function of distance above the droplet. A log scale is used to focus on chemistry at the plume base. The coarse grid solution shows higher temperature and BN mass fraction at the base of the plume compared to the nominal and fine grid solutions. The coarse grid solution clearly dissipates the $c_{B N}$ and temperature profile as the plume rises. In contrast, grid convergence is substantially achieved at the base of the plume for $z<0.1 \mathrm{~mm}$ across the recirculating flow as judged by agreement of the medium and fine grid results. Fig. 6(d) shows the evolution of the temperature profile at $5 \mathrm{~ms}$ intervals from the fine grid. The blue line in this figure shows a profile very early in the development of the plume at 0.2 $\mathrm{ms}$. The red line in this figure indicates the medium grid solution at $40 \mathrm{~ms}$. For $0.1<z<1 \mathrm{~mm}$ the medium grid solution starts to dissipate the higher curvature elements of the fine grid profiles. For $z>1 \mathrm{~mm}$ the plume growth on the medium grid starts to lag the growth on the fine grid as evident by the higher temperature profiles for a given time.

All observations relating to temporal evolution of the plume should be considered qualitative rather than quantitative. First, the axi-symmetric domain and boundary conditions restrict temporal evolution - the core of the plume is constrained to the centerline of the domain. Second, the assumption of a steady-state vaporization boundary condition requires a finite amount of time to set up. Given these caveats one notes that contour levels in the base of the plume set up very quickly. Consider, for example the line plot evolution of temperature in Fig. 6(d) where each line indicates the extent of the temperature profile in $5 \mathrm{~ms}$ increments. After only $15 \mathrm{~ms}$ the temperature at $z=$ $1 \mathrm{~mm}$ is within $5 \%$ of its value at $40 \mathrm{~ms}$. Species mass fractions follow the same trend.

A check of cell Reynolds numbers $R e_{\text {cell }}=\rho w \Delta x / \mu$ across the diffusion layer of the plume on the nominal grid indicate peak values as a function of pressure of 1.1 at 0 psig, 38 at 50 psig, 62 at 100 psig, 94 at 200 psig, 137 at 400 psig, and 241 at 800 psig. Given the small differences between the nominal and fine grid solutions at $200 \mathrm{psig}$ for $z>0.1 \mathrm{~mm}$ it is assumed that numerical dissipation affects the solution for at least $R e_{\text {cell }}>90$. For $z<0.1 \mathrm{~mm}$ the diffusion layer is better resolved with at least an order of magnitude reduction in cell size at the foot of plume where gas flow is predominantly in the radial direction. Evidence of grid convergence in the plume base is critical because the conditions here drive subsequent plume evolution and define maximum available reservoir levels of $\mathrm{BN}$.

\section{Chamber Pressure Effects}

Comparisons of the plume shape and properties at 0 psig (atmospheric pressure) and 200 psig (14.6 atmospheres) are presented in Figs. 7 and 8. The plume radius expands from the base at 0 psig and contracts at $200 \mathrm{psig}$ for the same delivered power level of .1 $\mathrm{kW}$. The vertical black line in these figures to the left and right of the axis indicate the $1 \mathrm{~mm}$ radius corresponding to the radius 


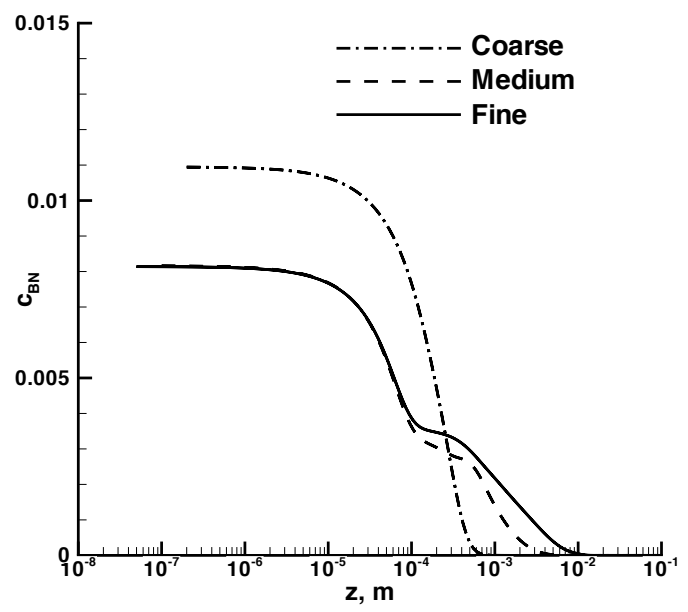

(a) mass fraction of $\mathrm{BN}, \mathrm{t}=0.04 \mathrm{~s}$

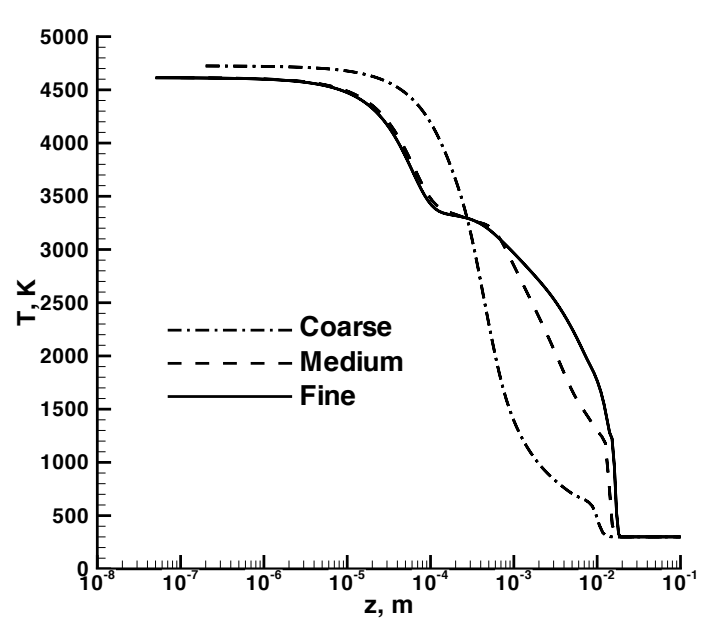

(c) temperature, $\mathrm{t}=0.04 \mathrm{~s}$

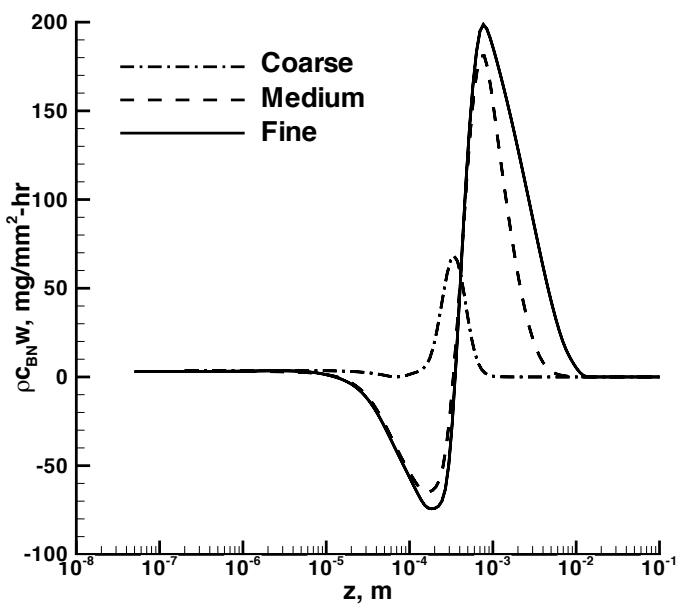

(b) flow rate of $\mathrm{BN}, \mathrm{t}=0.04 \mathrm{~s}$

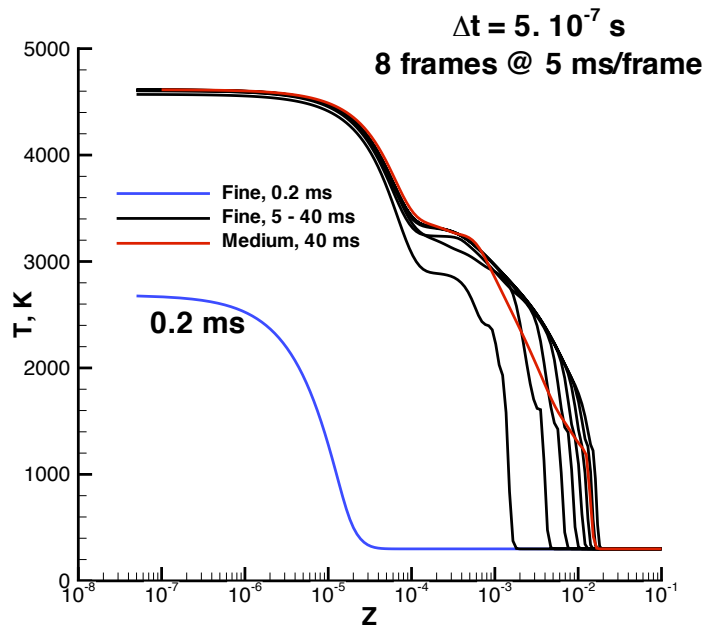

(d) temperature evolution on finest grid

Figure 6. Centerline variation of properties in a rising plume of gas over an irradiated droplet of Boron as function of grid and time. 
of the irradiated spot on the boron droplet on the floor of the domain. Peak temperature at the base and peak mass fraction of BN are higher for the 200 psig case compared to the 0 psig case. However, the BN mass fraction at 200 psig declines more quickly. The corresponding flow rates of boron derived species rising to the condenser loop (not shown) are presented for BN in Fig. $8(\mathrm{a})$ and for the sum of $\mathrm{B}$ and $\mathrm{B}_{2}$ in Fig. 8(b). There is no recirculation pattern at the base of the plume at 0 psig. Results indicate that $\mathrm{BN}$ returns to $\mathrm{B}_{2}$ and $\mathrm{N}_{2}$ as the plume rises and cools under assumption of equilibrium chemistry and under the assumption of single phase flow. The single phase flow assumption forces a supersaturated level of $\mathrm{BN}$ and $\mathrm{B}$ in the rising plume. The equilibrium flow assumption may deplete BN faster than collisional processes would allow because the availability of suitable atomic collision partners is diminished in the rising plume as it cools. This question will be revisited in the next section on Gas Chemistry Model Effects.

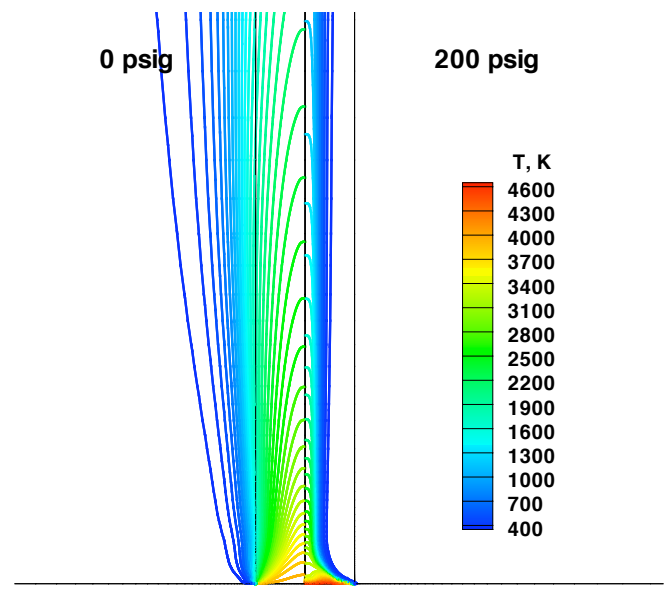

(a) Temperature

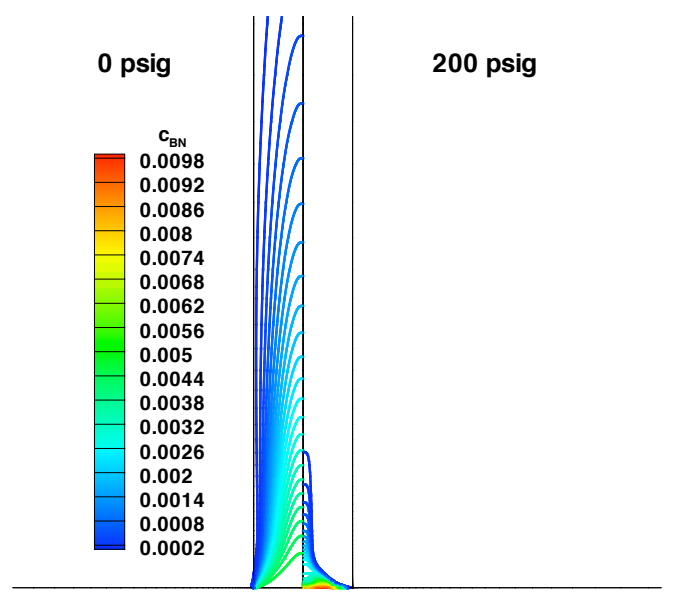

(b) Mass fraction BN

Figure 7. Comparison of plumes at 0 psig (left) and 200 psig (right).

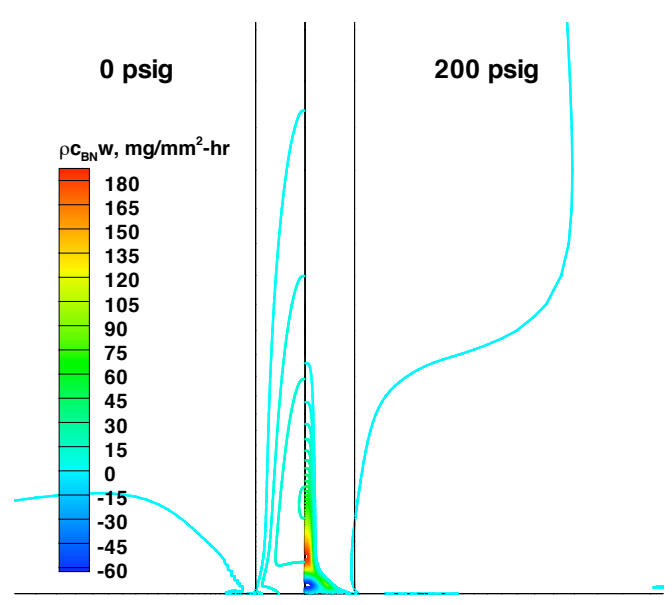

(a) Flow rate of $\mathrm{BN}$

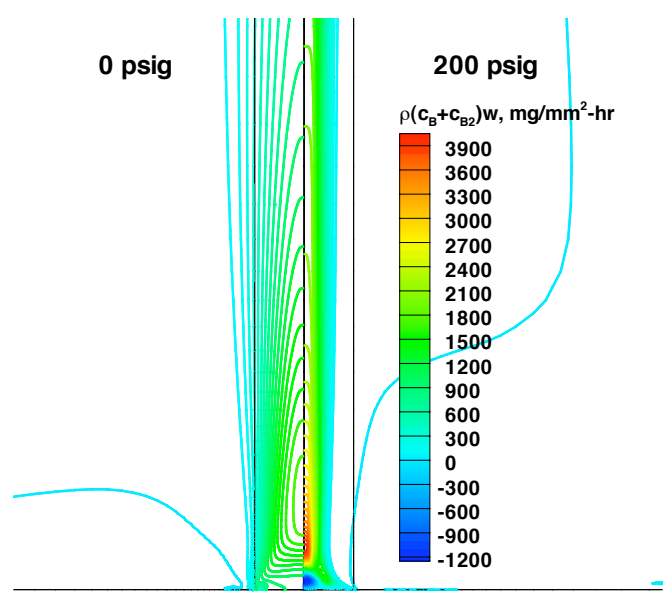

(b) Flow rate of $\mathrm{B}$ and $\mathrm{B}_{2}$

Figure 8. Comparison of Boron vertical flow rates at 0 psig (left) and 200 psig (right).

Figures 9 - 11 are intended to capture maximum values of key plume environmental variables that tend to drive plume dynamics. These maximum values occur at or near the base of the 
plume where grid resolution is thought to be adequate (based on the earlier Grid Convergence discussion) to establish the trends associated with chamber pressure. The figures show results as a function of total chamber pressure on the left and as a function of partial pressure of nitrogen in the chamber on the right. Helium and argon are added to the parametric study here to investigate if the presence of a lighter or heavier noble gas may influence the environment in a way to enhance the flow rate of boron-richgases. (The results shed no light regarding how the presence of noble gases may effect nucleation rates.) Isolating the effect of nitrogen partial pressure is intended to capture the importance of the availability of nitrogen as a reaction partner with boron at the base of the plume. There is no evident advantage to diluting the nitrogen atmosphere with a noble gas based on these results.

The figures show a clearly defined peak for BN mass fraction and flow rate between 50 and 200 psig. The maximum values are highest for a pure nitrogen atmosphere though the trends are evident in all of the tested atmospheres. It is thought that rapidly rising temperature between 0 and 100 psig accounts for a greater availability of atomic nitrogen which dissociates at temperatures above 4000 K. Beyond 200 psig the increase in peak temperature tapers off (Fig. 11) while dissociation of nitrogen is suppressed for a given temperature as the pressure rises. Consequently, the production of $\mathrm{BN}$ diminishes beyond 200 psig. If nucleation from a supersaturated flow of $\mathrm{BN}$ is a significant driver to the BNNT production rate or nanotube length then this local maximum is an important process design environmental variable.

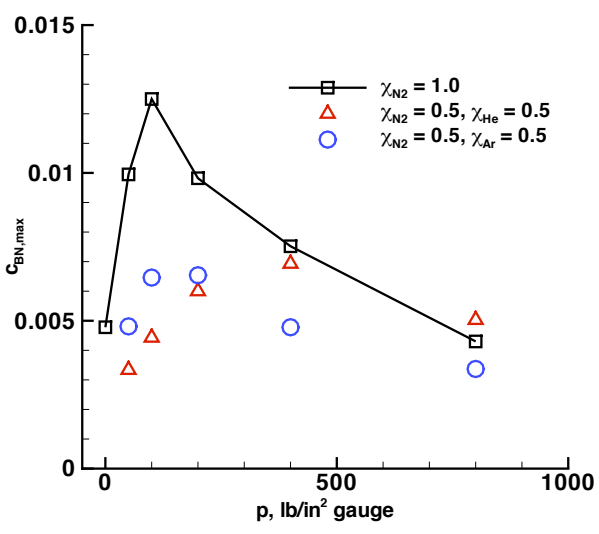

(a) total chamber pressure

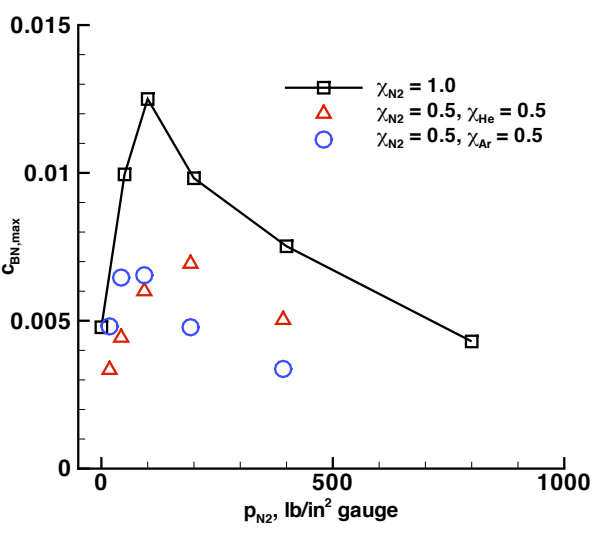

(b) nitrogen partial pressure in chamber

Figure 9. Variation of maximum BN mass fraction as a function of pressure and atmospheric consituents.

\section{Gas Chemistry Model Effects}

Earlier sections on Gas Properties and Chamber Pressure Effects discussed the concern that an equilibrium assumption may cause $\mathrm{BN}$ gas to be converted to $\mathrm{B}_{2}$ and $\mathrm{N}_{2}$ at an unnaturally high rate because of the limited availability of atomic collision partners. (This issue is related to the need for catalytic converters to break down exhaust gases from an automobile.) Two chemical kinetic models for the B-N system are proposed based on the C-N system as documented in Table 1. Kinetic model 1 includes all 5 reactions listed in Table 1 . Kinetic model 2 includes only the first 4 reactions listed in Table 1. It omits the final reverse reaction, effectively a double shuffle reaction, in which two molecular boron nitride molecules collide, dissociate, and then recombine 


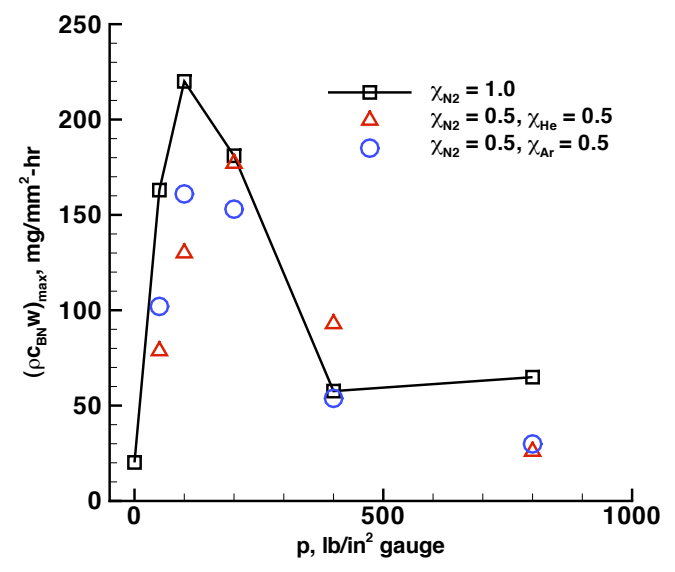

(a) total chamber pressure

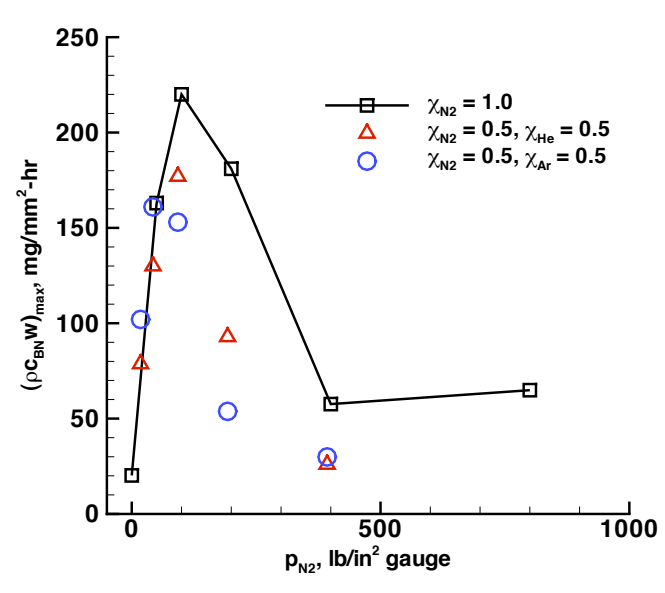

(b) nitrogen partial pressure in chamber

Figure 10. Variation of maximum vertical flow rate of $\mathrm{BN}$ as a function of pressure and atmospheric consituents.

into diatomic boron and diatomic nitrogen. Without this reaction, the only path to dissociate $\mathrm{BN}$ requires an atomic intermediary as either a collision partner (reactions 3 and 4 ) or a product (reaction 2). The template for reaction 5 had originally been proposed to explain dissociation of $\mathrm{CN}$ in a shock tube ${ }^{24}$ and later to explain measurements behind reflected shock waves ${ }^{25}$ but no such mechanism is used in kinetic models for air (O-N) systems.

Figure 12 compares mass fraction, BN flow rate and integrated flow rates across the plume as a function of height. In Fig. 12(a) the two kinetic models show identical levels of mass fraction $c_{B N}$ in the lower portion of the plume $(z<1 \mathrm{~mm})$ extending through the recirculating flow where $\mathrm{BN}$ is initially formed. The equilibrium model predicts approximately $10 \%$ lower values of $c_{B N}$ in this same region. For $z>1 \mathrm{~mm}$ kinetic model 1 approaches the equilibrium model while kinetic model 2 shows that BN persists as the plume continues to rise and cool. This trend is also evident in the vertical flow rate of BN in Fig. 12(b) where significant levels of BN persist beyond $2 \mathrm{~cm}$ to the top of the plume. The flow rate per unit area is integrated across the area of the plume out to $1 \mathrm{~mm}$ radius to show the flow rate of $\mathrm{BN}$ in $\mathrm{mg} / \mathrm{hr}$ in (c). An equivalent integration produces the combined flow rate of $\mathrm{B}$ and $\mathrm{B}_{2}$ in $\mathrm{mg} / \mathrm{hr}$. The $\mathrm{BN}$ flow levels using kinetic model 2 are small compared to $\mathrm{B}$ and $\mathrm{B}_{2}$ but the rate is roughly equivalent to estimated production rates of BNNTs in the PVC process. Kinetic model 2 results have no experimental validation. Its formulation using the C-N system template is thought to provide a credible example of how an actual flow would behave.

\section{E. Laser Power Effects}

The effects of absorbed laser power to a $1 \mathrm{~mm}$ radius spot on plume development are presented in Figs. 13 and 14. Simulated absorbed power levels include $.05 \mathrm{~kW}, 0.1 \mathrm{~kW}, 0.2 \mathrm{~kW}$, and $2.0 \mathrm{~kW}$ in a 200 psig chamber with $\chi_{N_{2}}=1$. Kinetic model 2 is employed in all simulations. The profiles are captured at $80 \mathrm{~ms}$.

As absorbed laser power increases the temperature at the base of the plume (Fig.13(a)) approaches the boiling point of boron as documented in Table 3. The boiling point is achieved at $2.0 \mathrm{~kW}$ and the blowing rate of boron completely displaces nitrogen at the bottom of the plume. 


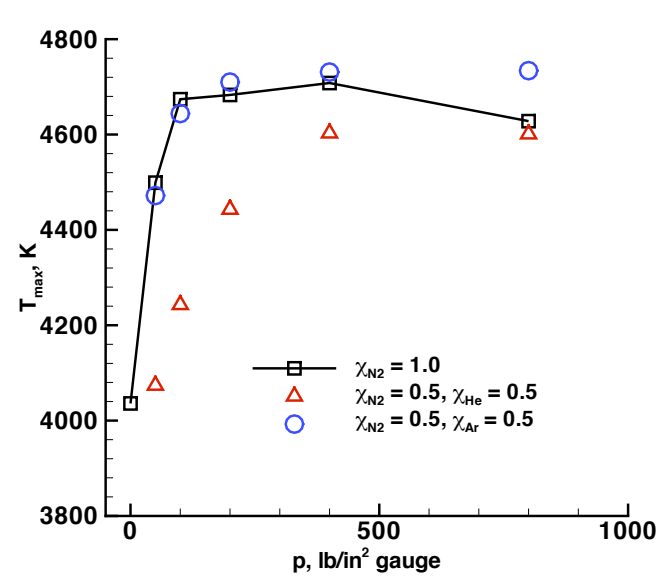

(a) total chamber pressure

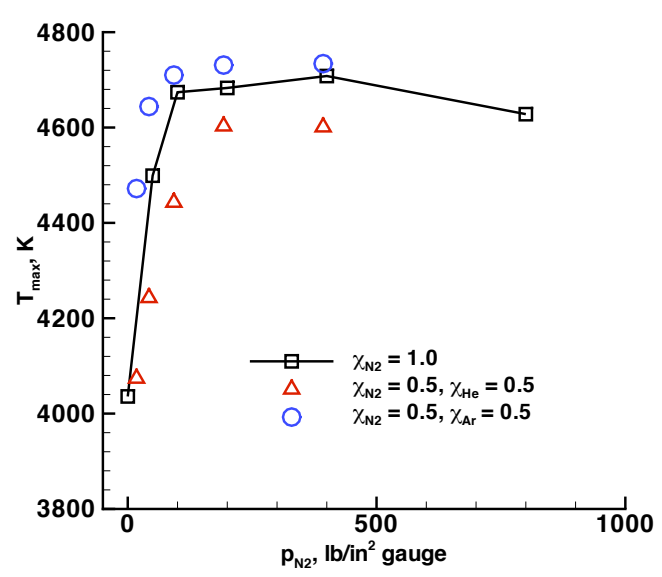

(b) nitrogen partial pressure in chamber

Figure 11. Variation of maximum temperature as a function of pressure and atmospheric consituents.

The sum of $c_{B}$ and $c_{B_{2}}$ equals 1 for $2.0 \mathrm{~kW}$ absorbed power (Figs.13(c) and (d)) and $c_{B N}$ goes to zero (Figs.13(b)) because no nitrogen is available to react with boron at the droplet surface. (The boiling droplet would not stay suspended from the fiber bundle in the current configuration - it is presented here as an interesting limiting condition.) A dip in the temperature profile at $z=0.1$ $\mathrm{mm}$ for the two lowest power levels is indicative of a recirculation pattern at the base of the plume. As power is increased, the blowing rate increases sufficiently to displace the recirculating flow.

Profiles of the flow rates of boron species are presented in Fig.14 for each of the four power levels. The centerline rates (Fig.14(a-b)) show the convective flux of boron containing species as a function of height. The integrated flow rate (Fig.14(c-d))plots the integral of the rising convective flux of boron containing species from $x=0$ (centerline) to $x=1 \mathrm{~mm}$ capturing the vertically convecting mass flux in the entire plume as a function of height. Note that these plots include only the vertical component of convective flux. This component represents almost $100 \%$ of the boron flux in the upper portion of the plume. If the plume is unsteady, there can be a significant horizontal component of flux. More importantly, for low blowing rates at lower absorbed power levels, the diffusive component of boron mass flux exceeds the convective component at the base of the plume.

The dashed lines in Fig.14(d) denote the vaporization rate of boron from the droplet surface. They are extended across the figure so that one may compare the instantaneous mass loss rate at $0.08 \mathrm{~s}$ to the vertical mass flux rate in the established plume. For the two lowest laser power cases agreement is excellent for $z>1 \mathrm{~mm}$. For the two highest power cases the simulated plume is unsteady, consequently the integrated flow rate shows variation as a function of height caused by pulsing as a function of time. The difference between the integrated convective flow rate and the vaporization rate for $z<0.01 \mathrm{~mm}$ indicates the level of diffusive flux of boron leaving the droplet.

The sustained integrated flow rate of $\mathrm{BN}$ in the upper part of the plume is approximately $3 \%$ of the vaporization rate for all of the power levels at 200 psig. These sustained levels essentially disappear if $\mathrm{BN}$ can form $\mathrm{B}_{2}$ and $\mathrm{N}_{2}$ at low temperatures without atomic intermediaries as forced by the chemical equilibrium approximation or as allowed in a kinetic model including reaction 5 of Table 1. These sustained levels could rise or fall depending on the kinetics of the real B-N system compared to the proposed system simulated here.

The computed integrated vaporization rate $\dot{\tilde{m}}$ for a feeder fiber bundle with density $\rho_{\text {rod }}$ and 


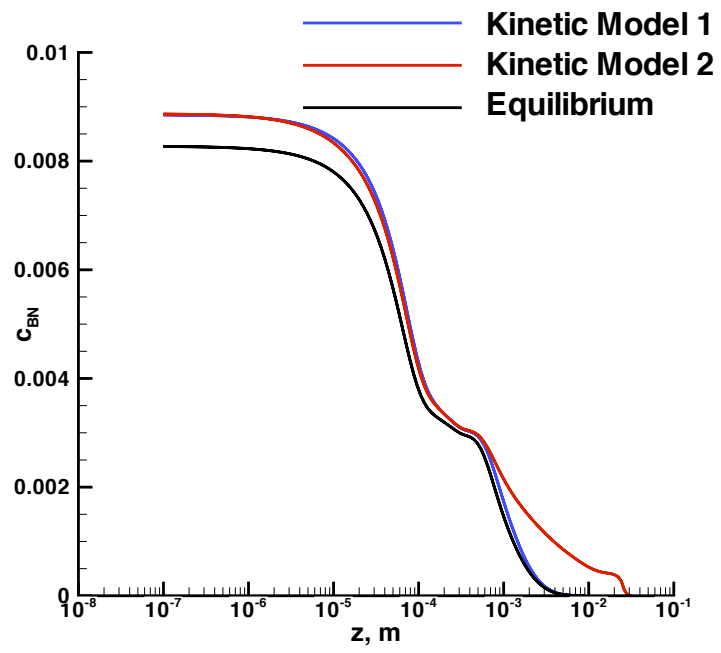

(a) mass fraction $\mathrm{BN}$

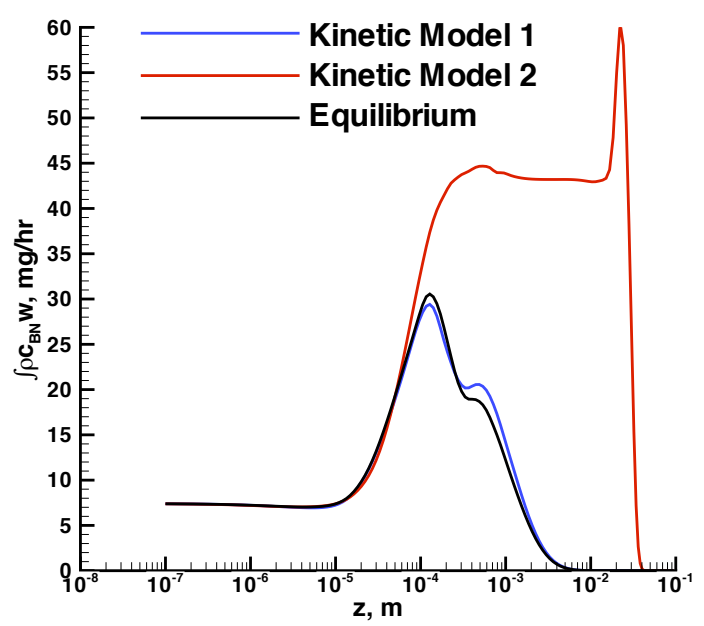

(c) integrated flow of $\mathrm{BN}$ across plume

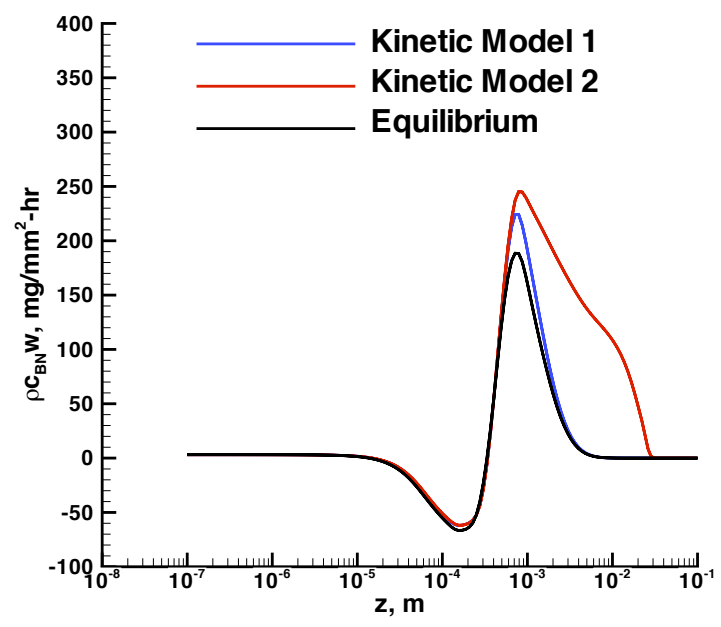

(b) vertical flow rate of $\mathrm{BN}$

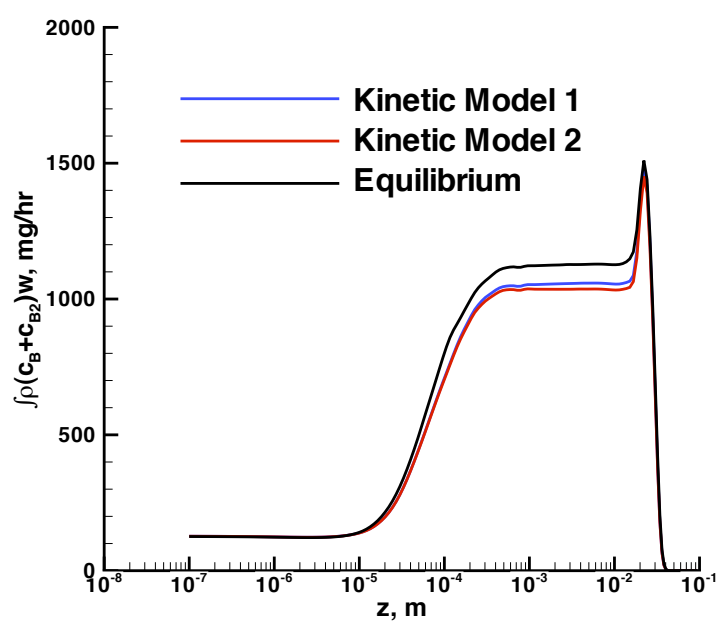

(d) integrated flow of $\mathrm{B}$ and $\mathrm{B}_{2}$ across plume

Figure 12. Centerline variation of properties in a rising plume of gas over an irradiated droplet of Boron as function of gas chemistry model. 


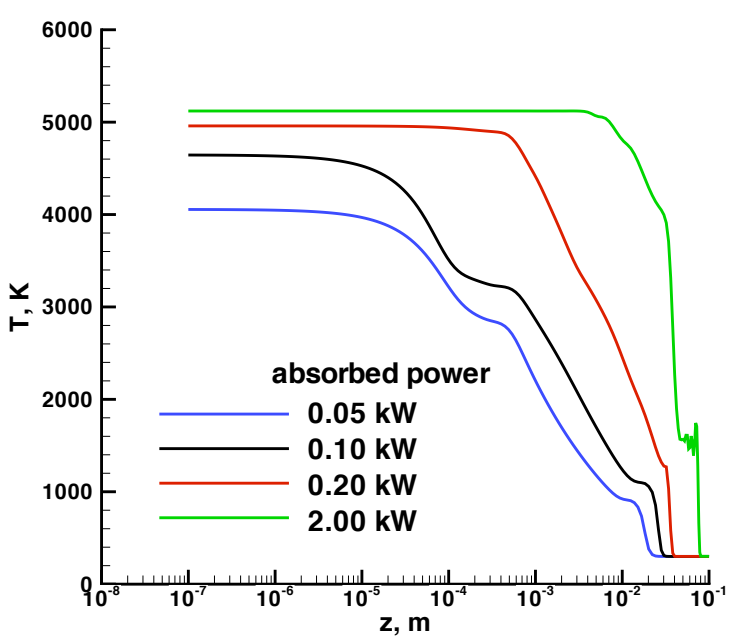

(a) temperature

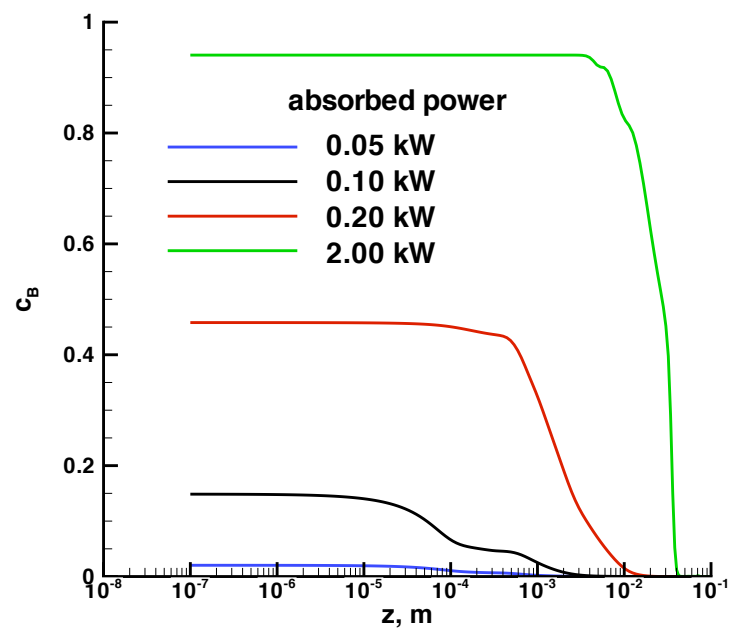

(c) mass fraction of $\mathrm{B}$

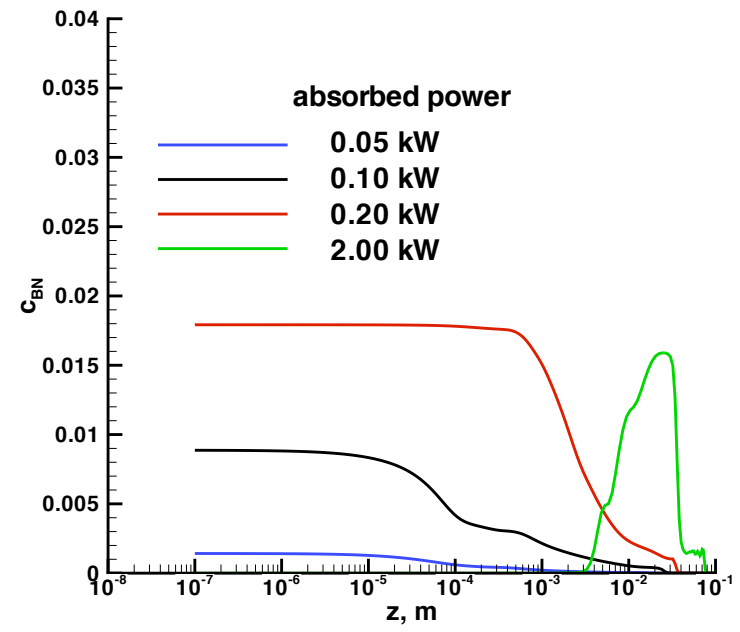

(b) mass fraction of $\mathrm{BN}$

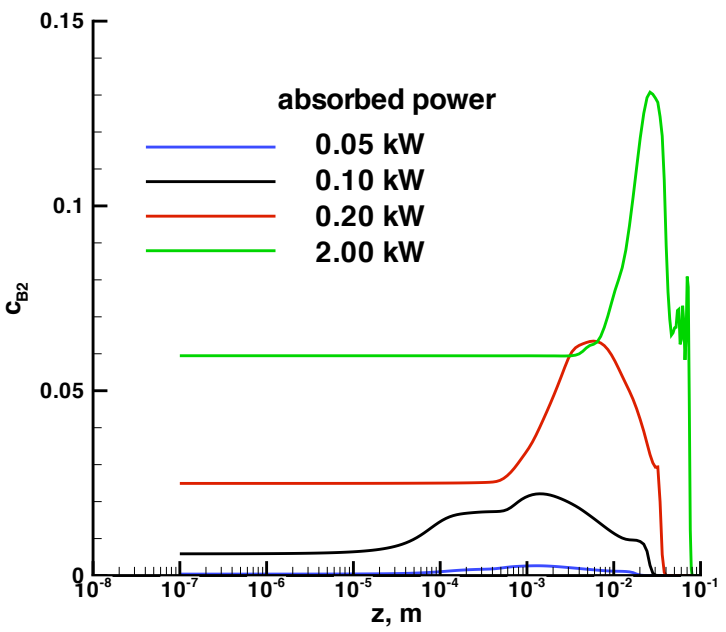

(d) mass fraction of $\mathrm{B}_{2}$

Figure 13. Centerline variation of thermodynamic properties in a rising plume of gas over an irradiated droplet of Boron as function of laser power. 


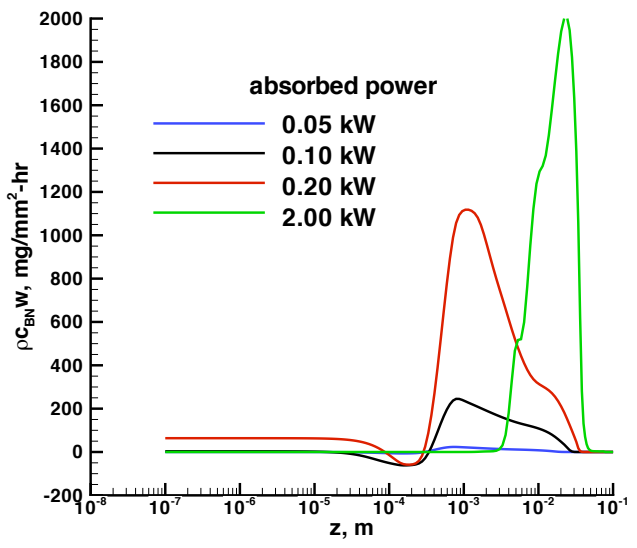

(a) centerline flow rate of $\mathrm{BN}$

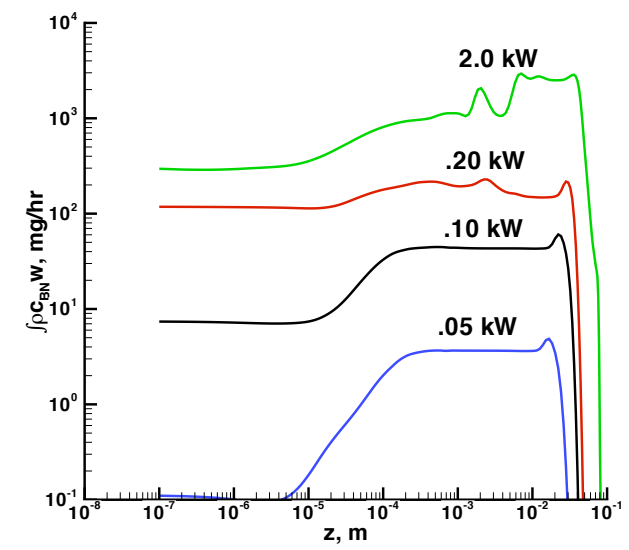

(c) integrated flow rate of $\mathrm{BN}$ across plume

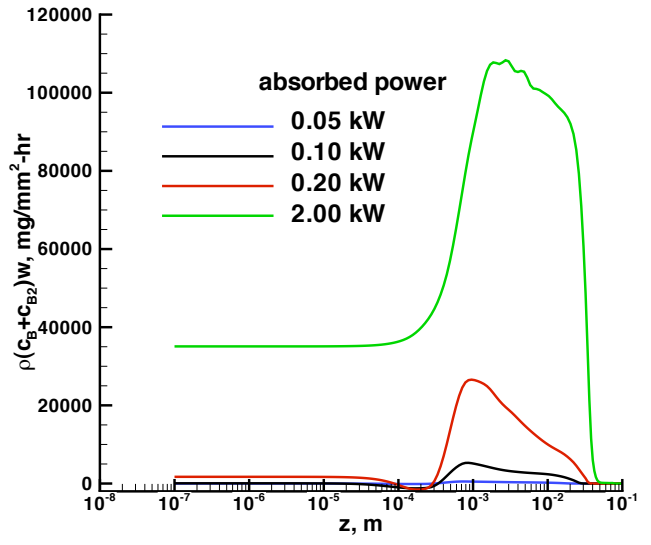

(b) centerline flow rate of $\mathrm{B}$ and $\mathrm{B}_{2}$

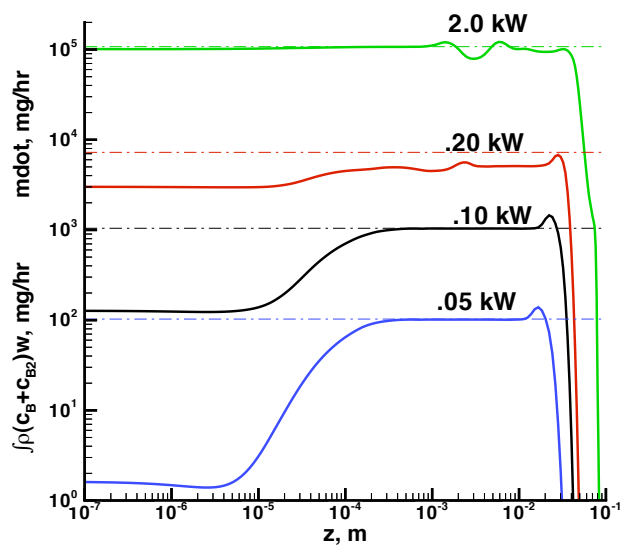

(d) integrated flow rate of $\mathrm{B}$ and $\mathrm{B}_{2}$ across plume

Figure 14. Variation of centerline and integrated production rates in a rising plume of gas over an irradiated droplet of Boron as function of laser power. Dashed lines indicate blowing rate at surface. 
radius $r_{\text {rod }}$ is easily transformed to the recession rate of the feeder fiber bundle $\dot{z}_{\text {rod }}$ with Eq. 6 .

$$
\dot{\tilde{m}}=\dot{z}_{\text {rod }} \rho_{\text {rod }} \pi r_{\text {rod }}^{2}
$$

Assuming a boron fiber bundle density $\rho_{\text {rod }}$ of $2.46 \mathrm{~g} / \mathrm{cm}^{3}$ the vaporization rates in Fig.14(d) transform to recession rates of $1.33 \mathrm{~cm} / \mathrm{hr}$ for $0.05 \mathrm{~kW}, 13.5 \mathrm{~cm} / \mathrm{hr}$ for $0.1 \mathrm{~kW}, 93.8 \mathrm{~cm} / \mathrm{hr}$ for $0.2 \mathrm{~kW}$ and $1393 \mathrm{~cm} / \mathrm{hr}$ for $2.0 \mathrm{~kW}$. For reference, the corresponding heating rates vary from 1592 $\mathrm{W} / \mathrm{cm}^{2}$ to $63662 \mathrm{~W} / \mathrm{cm}^{2}$ from the lowest to highest absorbed laser power levels. The fiber bundle recession rate will serve as a relatively simple metric to calibrate absorbed power after losses. Its utility will depend on ability to achieve a steady state vaporization condition without mechanical loss of droplets from the end of the feeder fiber bundle.

\section{Experimental Observations versus Simulations}

PVC process development has only recently included the simulation component described herein. Furthermore, the ability to execute these simulations has become available during a down time in which the production rig is being moved from the Department of Energy, Jefferson Lab in Newport News, Virginia to NASA Langley Research Center in Hampton, Virginia. Consequently, there has not yet been a concerted effort to gather experimental measurements for validation of the simulations. The BNNT apparatus became operational again at NASA Langley on May 17, 2012 and such validation experiments are currently in the planning stages. Two key production process observations ${ }^{26}$ are noted and discussed here.

It is observed that significant condensate forms on the condenser loop at locations from approximately $1 \mathrm{~cm}$ to $7 \mathrm{~cm}$ above the droplet surface. Nominal grid solutions indicate that it takes 0.16 seconds for the top of the plume to rise to a height of approximately $5 \mathrm{~cm}$. The plume is still slowly rising at this point in time. Plume simulations show greater attained height at equivalent times with greater delivered laser power (lower assumed losses). However, with the current modeling of steady state ablation from a spot on the floor of the chamber these higher power simulations indicate a greater recession rate than estimated from observations. Small perturbations to the current models may make the plume rise faster - for example, reducing the estimated laser spot diameter while increasing delivered power. A better solution is to increase fidelity of the laser - droplet - fiber bundle interaction region by expanding the simulation to include the domain around the suspended droplet. This modification exposes more droplet surface to feed the plume and allows an upwelling of nitrogen from below the droplet to potentially assist loft.

It is observed that the "cotton-like" condensate produced at a rate of 50 to $100 \mathrm{mg} / \mathrm{hr}$ contains up to $50 \%$ nanotubes by mass. The remaining condensate includes BN particle flakes and solidified boron droplets. Nanotubes are most often seen extending from these droplets suggesting that liquid boron droplet sites are critical to the nucleation of BNNT nanotubes. In the process described by Arenal et al. ${ }^{27}$ and Lee et al. ${ }^{20}$ it is assumed that liquid boron assists in the catalysis of molecular nitrogen to build the BN nanotube from the root. The simulations here suggest that a supersaturated state of $\mathrm{BN}$ gas in the plume provides a reservoir from which extremely rapid condensation of nanotubes progresses when a "suitable" nucleation site is encountered. The saturated equilibrium vapor pressure of boron with liquid boron, $p_{B, s a t}$, and the saturated equilibrium vapor pressure of $\mathrm{BN}$ with hexagonal boron nitride solid, $p_{B N, s a t}$, are calculated as a function of temperature using Eq. 4. Estimated reference triple point conditions used in Eq. 4 for BN are $p_{B N}=400 \pm 20$ $\mathrm{Pa}^{28} T_{B N}=3400 \pm 20 \mathrm{~K},{ }^{28}$ and $H_{B N, \text { sub }}^{0}=669.44 \mathrm{~kJ} / \mathrm{mol}^{14}$ The reference conditions for B were already discussed in the section on Material Response Model. The local vapor pressure of B and $\mathrm{BN}$ non-dimensionalized by the corresponding saturated vapor pressure is presented in Fig. 15 . The supersaturation factors exceed 100 for $z>1 \mathrm{~mm}$. The simulated mass flux levels of BN, B, and $\mathrm{B}_{2}$ are sufficiently high to produce the observed levels of condensate formed in the chamber. 


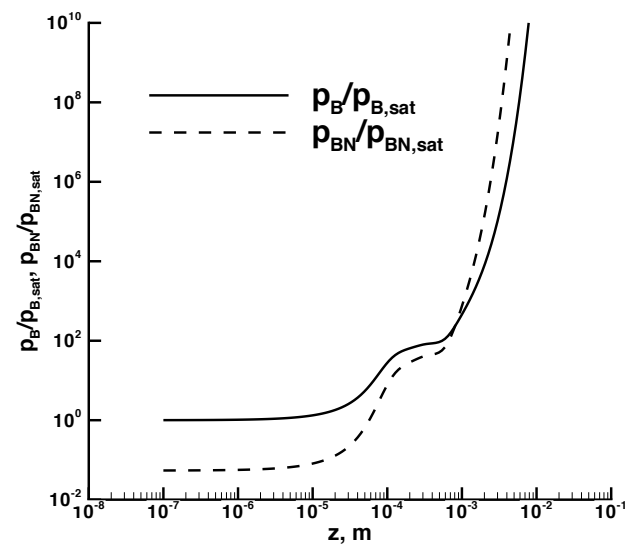

Figure 15. Profiles of $B$ and BN vapor pressure non-dimensionalized by the corresponding saturation vapor pressure as a function of distance above the droplet at $p_{0}=200 \mathrm{psig}$ using kinetic model 2.

Finally, we note that as chamber pressure is increased above 100 psig for absorbed laser power equal to $0.1 \mathrm{~kW}$ a recirculation region forms at the base of the plume. Recirculation provides extended residence time in a BN-rich environment for any particles (potential nucleation sites) that enter this region. As noted previously, higher absorbed power levels tend to increase the vaporization rate and displace any recirculation pattern.

\section{Summary}

Flow in a pressurized, vapor condensation (PVC) boron nitride nanotube (BNNT) production rig is modeled within Program LAURA. A laser provides a thermal energy source to the tip of a boron fiber bundle in a high pressure nitrogen chamber. The thermal energy source causes a molten droplet to form at the end of the fiber bundle. The boiling point temperature of boron increases with an increase in chamber pressure. The droplet temperature also rises with increasing chamber pressure for a given absorbed power level under assumptions of equilibrium vapor pressure and steady state vaporization. A plume of boron-rich gas rises from the droplet surface. The buoyancy driven flow is modeled as mixture of thermally perfect gases $\left(\mathrm{B}, \mathrm{B}_{2}, \mathrm{~N}_{1} \mathrm{~N}_{2}, \mathrm{BN}\right.$ ) in either thermochemical equilibrium or chemical nonequilibrium assuming steady-state melt and vaporization.

An idealized, axisymmetric chamber is used to model the PVC process. The droplet is positioned on the chamber floor at the axis, a $1 \mathrm{~mm}$ radius spot is irradiated, and a time-dependent evolution of the plume is simulated. Parametric simulations involving chamber pressure, equilibrium and non-equilibrium gas models, laser power levels, and dilution of nitrogen with noble gases in the chamber are executed. The simulations are intended to define the macroscopic thermochemical environment from which boron-rich species, including nanotubes, condense out of the plume. Only the gas phase is considered. Flow rates of $\mathrm{BN}$ vapor are monitored on the assumption that they could contribute to enhanced nucleation rates of BNNTs. The simulations for a nominal condition defined by $p_{0}=200 \mathrm{psig}$ and absorbed laser power of $0.1 \mathrm{~kW}$ to a $1 \mathrm{~mm}$ radius spot on a molten boron droplet indicate:

1. A high temperature environment $(T>4400 \mathrm{~K})$ forms within $1 \mathrm{~mm}$ of the surface at elevated chamber pressures $\left(p_{0} \geq 50 \mathrm{psig}\right)$ sufficient to dissociate molecular nitrogen and form BN at 
the base of the plume.

2. $\mathrm{BN}$ vapor flow rate exhibits a maximum at the plume base for $p_{0}$ somewhere between 50 and 200 psig.

3. Under an equilibrium chemistry model $\mathrm{BN}$ is transformed to $\mathrm{B}_{2}$ and $\mathrm{N}_{2}$ as gas rises and the plume cools.

4. Under a chemical kinetic model $\mathrm{BN}$ vapor flow levels are frozen as the plume continues to rise. The $\mathrm{BN}$ flow rate is approximately $3 \%$ of the net vaporization rate at $p_{0}=200$ psig for absorbed laser power varying from $0.05 \mathrm{~kW}$ to $2.0 \mathrm{~kW}$

5. A recirculation region begins to form at the base of the plume at $p_{0}=100$ psig. Recirculation provides any existing particulates an opportunity for extended residence time in a BN rich environment, even with the equilibrium gas model.

The simulations indicate that the high pressure environment causes significant levels of $\mathrm{BN}$ vapor in the plume that are not present at atmospheric pressure. We believe that a supersaturated reservoir of $\mathrm{BN}$ vapor is a significant contributor to the formation of high quality BNNTs produced in the PVC process. This theory still requires experimental validation that the physical models used in the simulation of the macroscopic environment of the plume are sufficiently accurate. The theory also requires simulations of the nucleation process itself to evaluate conditions that favor formation of nanotubes as opposed to the formation of amorphous particles of boron and boron nitride.

\section{Acknowledgements}

The authors thank Michael Smith (BNNT, LLC) and Kevin Jordan (Jefferson Lab) for sharing their experience in developing the PVC process and providing descriptions of the laser - droplet interaction. Conversations with them regarding possible impact of the role of high pressure environment helped guide some parametric studies executed herein. Cheol Park (National Institute of Aerospace) and Paul Danehy (NASA Langley) provided several constructive suggestions for improving figures and revising narrative. Figure 1 was originally prepared by Mike Smith and provided by Cheol Park.

\section{References}

\footnotetext{
${ }^{1}$ Arenal, R., Blase, X., and Loiseau, A., "Boron-nitride and boron-carbonitride nanotubes: synthesis, characterization and theory," Advances in Physics, Vol. 59, No. 2, 2010, pp. 101-179.

${ }^{2}$ Smith, M. W., Jordan, K. C., Park, C., Kim, J.-W., Lilleheil, P. T., Crooks, R., and Harrison, J. S., "Very long single- and few-walled boron nitride nanotubes via the pressurized vapor/condenser method," Nanotechnology, Vol. 20, No. 50, Nov. 2009, pp. 1-6.

${ }^{3}$ Smith, M. W. and Jordan, K., "Boron Nitride Nanotube Fibrils and Yarns," U. S. Patent Application Publication US 2010/0192535 A1, Aug 2010.

${ }^{4}$ McBride, B. J., Zehe, M. J., and Gordon, S., "NASA Glenn Coefficients for Calculating Thermodynamic Properties of Individual Species," NASA TP 2002-211556, September 2002.

${ }^{5}$ Gnoffo, P. A., Gupta, R. N., and Shinn, J. L., "Conservation Equations and Physical Models for Hypersonic Air Flows in Thermal and Chemical Nonequilibrium," NASA TP 2867, Feb. 1989.

${ }^{6}$ Ryabov, V. V., "Transfer Coefficient of Multicomponent Air with Sublimation Products of Graphite," Journal of Engineering Physics and Thermophysics, Vol. 55, No. 1, 1988, pp. 786-791.

${ }^{7}$ Riabov, V., "Approximate Calculation of Transport Coefficients of Earth and Mars Atmospheric Dissociating Gases," J. Therm. and Heat Trans., Vol. 10, No. 2, Oct. 1996, pp. 209-216.

${ }^{8}$ Wright, M. J., Hwang, H. H., and Schwenke, D. W., "Recommended Collision Integrals for Transport Property Computations Part 2: Mars and Venus Entries," AIAA J., Vol. 45, No. 1, Jan. 2007, pp. 281-288.
} 
${ }^{9}$ Levin, E., Stallcop, J. R., and Partridge, H., "Transport properties of boron and aluminum," Theor Chem Acc, Vol. 103, 2000, pp. 518-523.

${ }^{10}$ Stallcop, J. R., Partridge, H., Pradhan, A., and Levin, E., "Potential Energies and Collision Integrals for Interactions of Carbon and Nitrogen Atoms," J. Therm. and Heat Trans., Vol. 14, No. 4, 2000, pp. 480-488.

${ }^{11}$ Gnoffo, P., Johnston, C., and Thompson, R., "Implementation of Radiation, Ablation, and Free Energy Minimization Modules for Coupled Simulations of Hypersonic Flow," J. Spacecraft and Rockets, Vol. 47, No. 2, 2010, pp. 251-257.

${ }^{12}$ Fujita, K., Yamada, T., and Ishii, N., "Impacts of Ablation Gas Kinetics on Hyperbolic Entry Radiative Heating," AIAA Paper 2006-1185, Jan. 2006.

${ }^{13}$ Park, C., Jaffe, R. L., and Partridge, H., "Chemical-Kinetic Parameters of Hyperbolic Earth Entry," J. Therm. and Heat Trans., Vol. 15, No. 1, Jan. 2001, pp. 76-90.

${ }^{14}$ Chase, Jr., M. W., Davies, C. A., Downey, Jr., J. R., Frurip, D. J., McDonald, R. A., and Syverud, A. N., JANAF Thermochemical Tables, Third Edition, Part I, Al-Co, Journal of Physical and Chemical Reference Data, Vol. 14, Supplement No. 1, American Chemical Society and American Institute of Physics for National Bureau of Standards, 1985.

${ }^{15}$ Mazaheri, A., Gnoffo, P. A., Johnston, C. O., and Kleb, B., "LAURA Users Manual: 5.3-48528," NASA TM 216836, August 2010.

${ }^{16}$ Roe, P. L., "Approximate Riemann Solvers, Parameter Vectors, and Difference Schemes," J. Comput. Phys., Vol. 43, No. 2, Oct. 1981, pp. 357-372.

${ }^{17}$ Harten, A. and Hyman, J. M., "Self Adjusting Grid Methods for One-Dimensional Hyperbolic Conservation Laws," J. Comput. Phys., Vol. 50, 1983, pp. 235-269.

${ }^{18}$ Yee, H. C., "On Symmetric and Upwind TVD Schemes," NASA TM 88325, 1986.

${ }^{19}$ Gnoffo, P. A. and Johnston, C. O., "A Boundary Condition Relaxation Algorithm for Strongly Coupled, Ablating Flows including Shape Change," AIAA Paper 2011-3760, June 2011.

${ }^{20}$ Lee, R. S., Gavillet, J., de la Chapelle, M. L., Loiseau, A., Cochon, J.-L., Pigache, D., Thibault, J., and Willaime, F., "Catalyst-free synthesis of boron nitride single-wall nanotubes with a preferred zig-zag configuration," Physical Review B, Vol. 64, No. 121405, 2001, pp. 1-4.

${ }^{21}$ Moon, W. H. and Hwang, H. J., "Molecular-dynamics simulation of structure and thermal behaviour of boron nitride nanotubes," Nanotechnology, Vol. 15, 2004, pp. 431-434.

${ }^{22}$ Blase, X., Vita, A. D., Charlier, J.-C., and Car, R., "Frustration Effects and Microscopic Growth Mechanisms for BN Nanotubes," Physical Review Letters, Vol. 80, No. 8, 1998, pp. 1666-1669.

${ }^{23}$ Wang, C. and Yang, G., "Thermodynamics of metastable phase nucleation at the nanoscale," Materials Science and Engineering R, Vol. 49, 2005, pp. 157-202.

${ }^{24}$ Patterson, Jr., W. L. and Greene, E. F., "Kinetic Study of the Formation and Reaction of CN Molecules in Shock Waves," The Journal of Chemical Physics, Vol. 36, No. 5, March 1962, pp. 1146-1151.

${ }^{25}$ Sommer, T., Kruse, T., Roth, P., and Hippler, H., "Perturbation Study on the Reaction of $\mathrm{C}_{2}$ with $\mathrm{N}_{2}$ in High-Temperature $\mathrm{C}_{60} / \mathrm{Ar}+\mathrm{N}_{2}$ Mixtures," J. Phys. Chem. A, Vol. 101, No. 20, 1997, pp. 3720-3725.

${ }^{26}$ Smith, M., Private communication with subcontractor, InterAgency Agreement-1103, NASA LaRC and Department of Energy, 2012.

${ }^{27}$ Arenal, R., Stephan, O., Cochon, J.-L., and Loiseau, A., "Root-Growth Mechanism for Single-Walled Boron Nitride Nanotubes in Laser Vaporization Technique," J. Am. Chem. Soc., Vol. 129, No. 51, 2007, pp. 16183-16189.

${ }^{28}$ Solozhenko, V. L., Turkevich, V. Z., and Holzapfel, W. B., "Refined Phase Diagram of Boron Nitride," J. Phys. Chem. B, Vol. 103, No. 15, 1999, pp. 2903-2905. 